\title{
Mortars with Recycled Aggregates from Building-Related Processes: A 'Four-Step' Methodological Proposal for a Review
}

\author{
Federica Vitale and Maurizio Nicolella *(D) \\ Department of Civil Architectural and Environmental Engineering (DICEA), University of Naples Federico II, \\ 80125 Naples, Italy; federica.vitale@unina.it \\ * Correspondence: maurizio.nicolella@unina.it; Tel.: +39-081-768-2141
}

check for updates

Citation: Vitale, F.; Nicolella, M. Mortars with Recycled Aggregates from Building-Related Processes: A 'Four-Step' Methodological Proposal for a Review. Sustainability 2021, 13, 2756. https://doi.org/10.3390/su 13052756

Academic Editor: John Myers

Received: 31 January 2021

Accepted: 26 February 2021

Published: 4 March 2021

Publisher's Note: MDPI stays neutral with regard to jurisdictional claims in published maps and institutional affiliations.

Copyright: (C) 2021 by the authors Licensee MDPI, Basel, Switzerland. This article is an open access article distributed under the terms and conditions of the Creative Commons Attribution (CC BY) license (https:/ / creativecommons.org/licenses/by/ $4.0 /)$.
Abstract: Because the production of aggregates for mortar and concrete is no longer sustainable, many attempts have been made to replace natural aggregates (NA) with recycled aggregates (RA) sourced from factories, recycling centers, and human activities such as construction and demolition works (C\&D). This article reviews papers concerning mortars with fine RA from C\&D debris, and from the by-products of the manufacturing and recycling processes of building materials. A fourstep methodology based on searching, screening, clustering, and summarizing was proposed. The clustering variables were the type of aggregate, mix design parameters, tested properties, patents, and availability on the market. The number and the type of the clustering variables of each paper were analysed and compared. The results showed that the mortars were mainly characterized through their physical and mechanical properties, whereas few durability and thermal analyses were carried out. Moreover, few fine RA were sourced from the production waste of construction materials. Finally, there were no patents or products available on the market. The outcomes presented in this paper underlined the research trends that are useful to improve the knowledge on the suitability of fine RA from building-related processes in mortars.

Keywords: circular economy; sustainability; construction and demolition works; secondary raw materials

\section{Introduction}

Spreading the idea of sustainability is one of the greatest challenges nowadays, both for scientific and civil communities. In fact, the world has to face the scarcity of natural resources, the need of raw materials, and the increasing amount of waste to be disposed of [1]. Due to the lack of balance among those instances, severe and immediate measures have to be taken. As a result, in the last few years, the whole scientific world has focused on the circular economy as a strategy which is useful both to reduce natural resource consumption and waste production, and to recycle and reuse the waste as secondary raw materials [2].

It is worth noting that the construction world is one of the most impactful human activities, as all of the phases of its process consume natural resources and produce waste [3]. With respect to the depletion of resources, concrete and mortar are two of the most used materials - twenty five billion tons per year [4] - and their volume is about $65-80 \%$ aggregates [1]. Because NA are mainly obtained by dredging river beds or by mining stone in quarries, they cause a significant environmental impact [5]. The waste from the construction world generally relates to the scrap materials produced at the building site during the construction and demolition. In Europe, the amount of C\&D waste is about $45 \%$ of the total European waste [6], and due to its high volume, it is necessary to find an alternative solution to its disposal because of the lack of available spaces for landfills [7]. As a consequence, $C \& D$ waste has been declared a European priority area, and several directives have been written in order to define mandatory targets for its recovery. Moreover, if the boundaries of the analysis are extended and the environmental impact of building 
materials production itself is considered, we can note that C\&D waste covers only a part of the whole 'construction world' waste. Because they are increasing their waste production from year to year [5], the factories which produce building materials are becoming an environmental issue, alongside other factories' by-products-e.g., plastic, glass-which are produced daily but slowly recycled [8].

The aforementioned instance of reducing both the waste production and the natural resource depletion due to aggregates has driven us - in the last few years-to investigate the feasibility of alternative aggregates sourced by recycling processes and so-called RA. The researchers have focused on several types of RA with various sources, sizes, and fields of use [9-12]. Many materials have been considered, such as plastic [13,14], ceramics [15], concrete [16], masonry [17], industrial and agricultural waste [18], and glass [19], along with several applications, such as concrete, mortars, pavements, and asphalt. However, while the concretes made with RA have been deeply examined, less is known about the mortars made with RA [2].

Two main categories of mortars and their relative performances are regulated by Italian (UNI) and European (EN) standards UNI EN 998-1 and 2:2016. Because the aggregates influence the performances and hence the field of use of RA mortars, this paper aims to investigate which are the most- and the least-employed types of RA in the current literature, and for which kind of mortars they are used. In order to achieve these purposes, a four-step methodology was employed in order to define and then analyze a set of one hundred and four papers written in the time interval 2015-2020. The data on the aggregates, mix proportions and tested properties were collected and then processed using two summarizing sequences. The results of this investigation may be useful to extend the research lines to the less-used RA, and the less-tested properties, with particular reference to RA related to building material factories, which are necessary to fulfill the circular economy targets for the construction world.

\section{Methodology}

The present study was based on a four-step methodology which aimed to analyze papers containing mortars with recycled aggregates from building-related processes, such as construction and demolition works (C\&D), and the production and recycling of building materials. The expression 'building-related processes' does not refer to the 'cradle component' of the fine RA, but rather to their chemical and physical properties. Hence, the fine RA do not have to be sourced from a factory which produces building components-e.g., tiles, bricks, windows-but it is necessary that the fine RA-source treats the materials of the building components, e.g., ceramics, plastic, glass. This means that plastic fine RA from recycled bottles - as well as ceramics from defective tiles-are included; agricultural or heavy metal waste are excluded, instead.

Both qualitative and quantitative analyses were conducted. The workflow consisted of searching, screening, clustering, and summarizing phases, as shown in Figure 1. Each phase is detailed in the subheadings below. From now on, the nouns 'records', 'papers' and 'articles' are used as synonyms, and the expression ' $\mathrm{RA}^{\prime}$ always refers to fine recycled aggregates. 


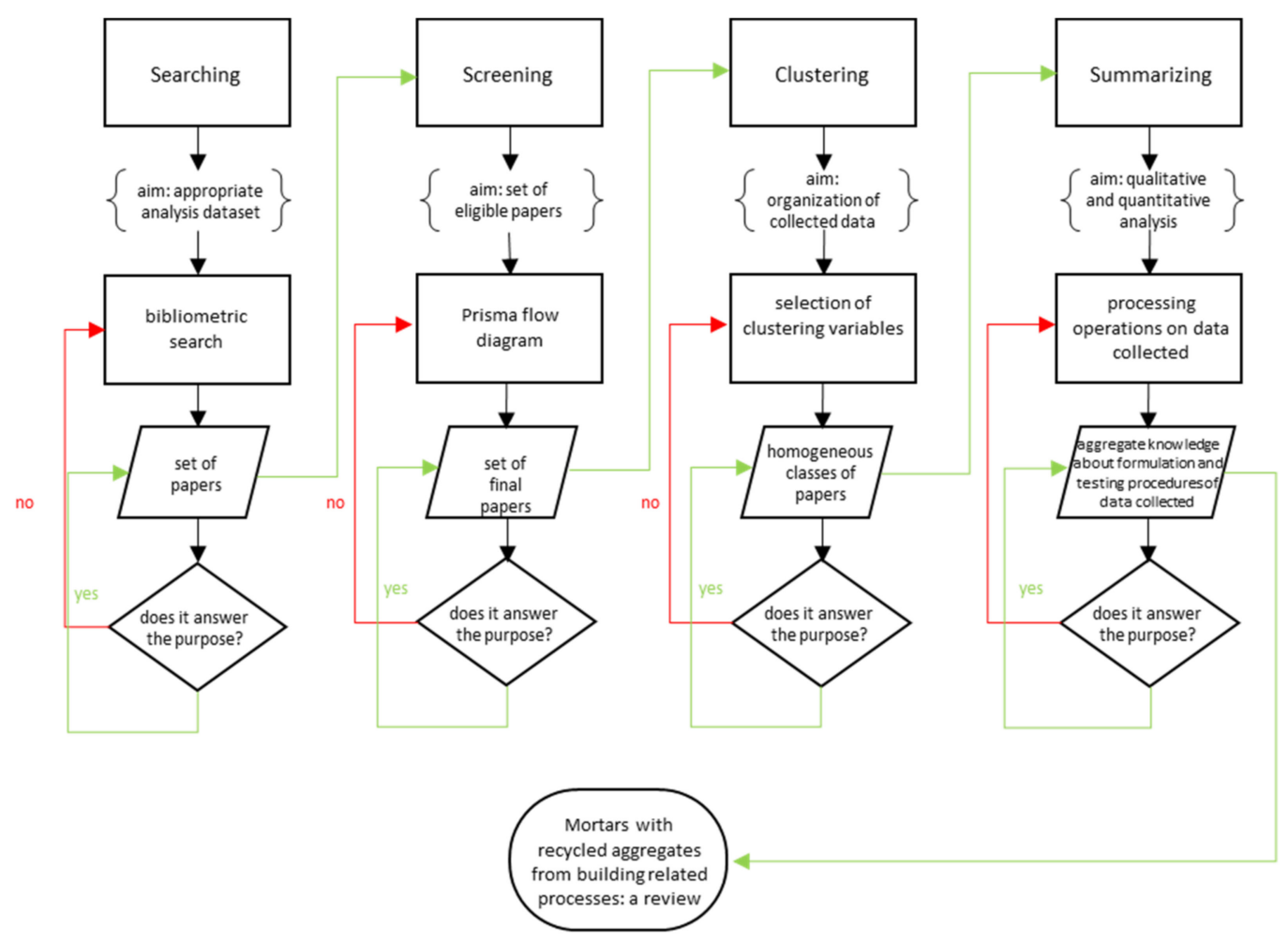

Figure 1. Four-phase workflow scheme. The rectangles indicate the processes, the parallelograms indicate the inputs and outputs of the processes, the rhombuses indicate the decisions, and the curly brackets indicate the aim of each phase. The rounded rectangle indicates the final point of the workflow.

\subsection{Searching}

This phase aimed to define an analysis dataset which fitted the purpose of the study. A bibliometric search of the literature was carried out in order to compose the starting set of papers. The searching database, time interval, type of paper, and search queries were chosen as the bibliometric parameters. Only full papers were recruited for this literature review.

In the first stage, the papers were sourced from Science Direct, with a time interval of ten years (2010-2020) and several search queries. The database filter "research articles" was employed in order to select the experimental papers. The search was limited to "research articles" because this study needed experimental data about the formulation and the characterization of mortars with RA. The Boolean operators AND, OR and NOT were used to define the search strings. The searching database tool "find articles with these terms" was employed, and no further filters were applied on the title or the abstract. Firstly, the most general input "recycled AND aggregate" was given, followed by "recycled AND mortar", "recycled AND aggregate AND conglomerate", "recycled AND aggregate AND mortar" and finally "recycled AND aggregate AND mortar NOT concrete". Because the present study reviews mortars with RA, the last string was used to exclude the papers which analysed concrete with RA. The use of singular or plural nouns in the strings did not affect the search results.

Because of the high number of papers which suited the queries, in the second stage, some of the searching parameters were changed, as described below. The same database and type of paper of the preliminary stage were employed, whereas the time interval was reduced to six years (2015-2020) and a filter on the title was added. The papers were searched with "recycled AND aggregate AND mortar AND TITLE mortar", and with "recycled AND aggregate AND rendering AND TITLE rendering". The keyword "rendering" substituted "mortar" in order to narrow the search field down, and to focus on a specific ap- 
plication of the mortars. The query "recycled AND aggregate AND conglomerate"-from the first stage —-was repeated with the time interval 2015-2020.

\subsection{Screening}

The analysis dataset of the searching phase was deeply examined in order to select the papers which suited the eligibility criteria, in accordance with the Prisma flow diagram [20].

Firstly, the duplicates, the unpublished articles, and the papers not written in English were removed. Then, the records of each search query were assessed with respect to the following eligibility criteria:

- The object of the record. This criterion was used to eliminate the papers which did not answer the aim of the present study. Firstly, the articles which focused on geopolymers, concretes, and conglomerates for road asphalt or pavements were excluded. In fact, the formulation, the mixing procedure, and the chemical-mineralogical characteristics of geopolymers differ from traditional mortars. Secondly, because different types of conglomerate require specific laboratory tests, in accordance with the regulations, the papers about concretes and conglomerates for road applications were excluded, because the data they produced were beyond the interest of this review.

- The source of the RA. This filter eliminated the papers which employed sludge, since sludge is a highly heterogeneous material, and its consistency is not solid. Moreover, RA sourced from food industry waste or from biomasses were excluded because of their organic matter, as well as the RA containing hazardous or toxic materials from heavy industries, because of the supplementary treatments they need.

- The role of the RA. Papers in which the RA substituted the binder-rather than being used as an aggregate-were removed from the analysis dataset.

After the assessment, the final dataset of articles was available.

\subsection{Clustering}

The purpose of this phase was to organize the collected data of the final dataset. An Excel database was created, and an ID number was assigned to the records. Then, each article was opened and the data about general information - the title, year of publication, journal of publication, keywords, authors, object of the study, presence or lack of patents, availability on the market-mix design, and testing procedures were manually entered. The data were both textual and numerical. The textual data were recorded with 'yes' or 'no', depending on the presence or the lack of the variable, respectively; the numerical data were reported with their value and unit of measurement. If more than one mix was analysed in the record, only the data corresponding to the mixes with the maximum and minimum values were reported in the Excel database.

Then, four macro-clustering variables (A, B, C, and D) were defined on the basis of the data collected:

- A: type of aggregate,

- B: mix design,

- C: tested properties,

- D: patents and availability on the market.

A tree structure was created; the general clustering variables-A, B, C, and D-were on the top as 'root nodes', then new layers of 'branch nodes' were added, and the variables were progressively detailed until the bottom level of 'leaf nodes' was defined and no further 'ramifications' were found.

The aggregates were coded in relation to their source:

- $\mathrm{A} 1: \mathrm{C} \& \mathrm{D}$,

- A2: factories and recycling centers.

An additional distinction was made in A2:

- A2.1: building materials factories, 
- A2.2: recycling centers.

Moreover, they were classified on the basis of their chemical nature. The A-variable classification is reported in Figure 2.

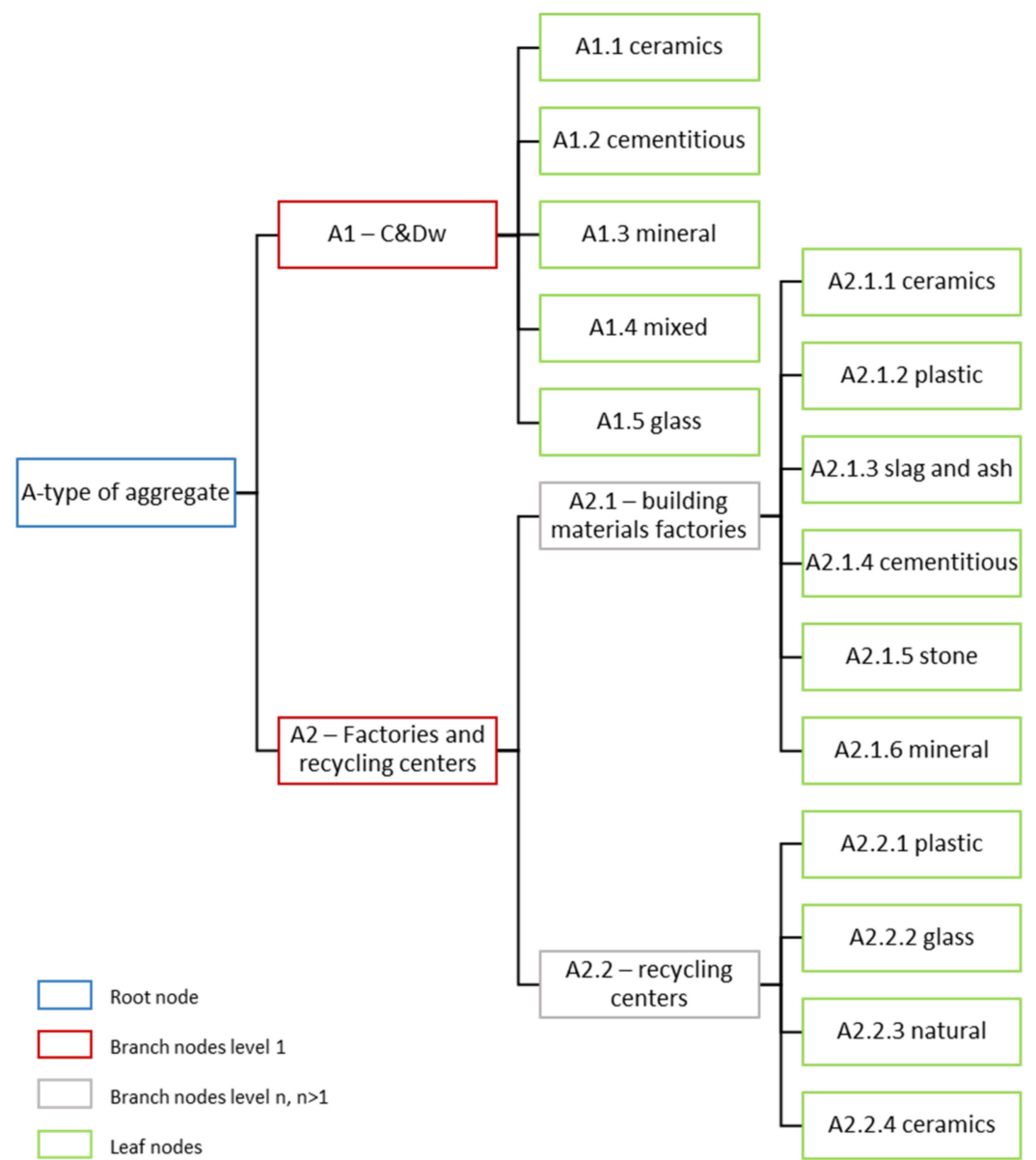

Figure 2. 'A-type of aggregate' classification. The aggregates were classified by their source (A1, A2) and materials (A1.1-A1.5; $\mathrm{A} 2.1 .1-\mathrm{A} 2.1 .6 ; \mathrm{A} 2.2 .1-\mathrm{A} 2.2 .4)$; the figure reports the hierarchical structure of the classification.

The B-variable included the data collected on the mix proportion among the constituents of the analysed mortars:

- B1: number of mixes,

- B2: recycled aggregates (RA) to natural aggregates (NA) ratio,

- B3: water to cement mass ratio,

- B4: aggregate to binder ratio,

- B5: superplasticizer or other additives.

Figure 3 reports the B-variable classification.

The data collected on the tested properties were grouped as described below:

- C1: physical properties,

- C2: mechanical properties,

- C3: durability,

- C4: thermal and hygrometric properties,

- C5: chemical and mineralogical properties,

- C6: sustainability issues including environmental and economic analyses. 


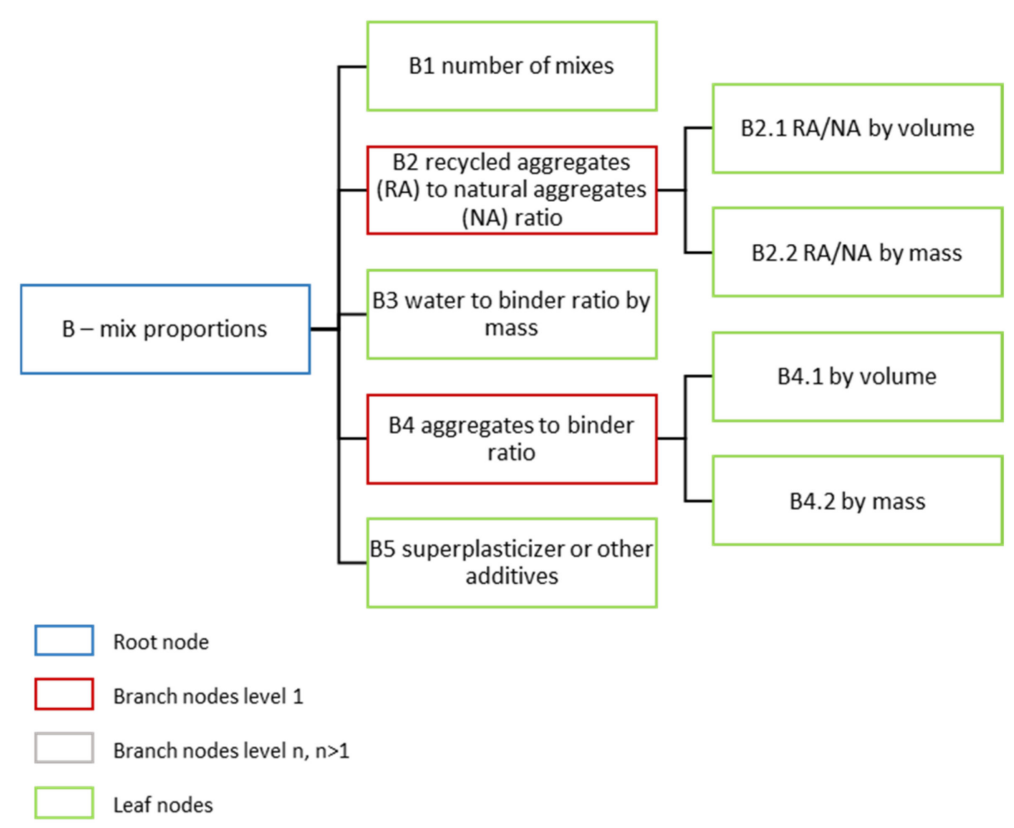

Figure 3. 'B-mix proportions' classification. The figure reports the hierarchical structure of the classification.

The classification of the C-variable is reported using a bulleted list in order to facilitate its understanding, whereas its hierarchical structure is reported in Figures A1-A3:

- C1.1: fresh state properties,

- C1.1.1: bulk density,

- C1.1.2: slump value,

- C1.1.3: viscosity,

- C1.1.4: air content,

- C1.2: hard state properties,

- C1.2.1: bulk density,

- C1.2.2: porosity,

- C1.2.3: water adsorption by total immersion,

- C1.2.4: water adsorption by capillarity $\left(\mathrm{g} / \mathrm{cm}^{3}\right)$,

- C1.2.5: water adsorption by capillarity coefficient $\left(\mathrm{kg} / \mathrm{m}^{2} \mathrm{~min}^{0.5}\right)$,

- C1.2.6: water adsorption by capillarity ( $\mathrm{mm})$,

- C1.2.7: water adsorption by capillarity rate ( $\mathrm{mm} / \mathrm{min})$,

- C2.1: 28-day compressive strength,

- C2.2: 28-day flexural strength,

- C2.3: elastic modulus,

- C2.3.1: 28-day elastic modulus,

- C2.3.2: 90-day elastic modulus,

- C2.4: 28-day bonding strength,

- C2.5: 28-day adhesion,

- C3.1: coefficient of Chloride diffusion,

- C3.2: 90-day chloride ion penetration,

- C3.3: alkali silica reaction expansion,

- C3.3.1: 14-day alkali silica reaction expansion,

- C3.3.2: 28-day alkali silica reaction expansion,

- C3.4: frost resistance,

- C3.5: accelerated ageing test with heat-freeze/freeze-thaw cycles,

- C3.6: permeability to water under pressure,

- C3.7: 28-day gas permeability coefficient,

- C3.8: 28-day sorptivity coefficient, 
- C3.9: carbonation depth after 28-day of carbonation,

- C3.10: drying shrinkage,

- C3.10.1: 28-day drying shrinkage (mm),

- C3.10.2: 28-day drying shrinkage (\%),

- C3.11: mass changes after drying and wetting cycles,

- C4.1: thermal properties,

- C4.1.1: thermal conductivity,

- C4.1.2: thermal diffusivity,

- C4.2: hygrometric properties,

- C4.2.1: vapor permeability,

- C4.2.2: resistance to vapor permeability,

- C5.1: X-Ray Diffraction (XRD),

- C5.2: Thermo Gravimetric Analysis (TGA),

- C5.3: Scanning Electronic Microscope (SEM),

- C5.4: Leaching test,

- C5.5: measure of acidity with $\mathrm{pH}$ test,

- C5.6: X-Ray Fluorescence spectroscopy (XRF),

- C6.1: Life Cycle Analysis (LCA),

- C6.2: economic viability.

The D-variable reported the presence of patents or other types of intellectual property protection (D1), and the availability of the tested mixes on the market (D2). These data gave information on the research development, and on the suitability of the collected mixes.

\subsection{Summarizing}

Two sequences were followed in this phase. In the first one, named S1, "A-type of aggregate" was selected as the driving variable, and the papers with the same A-leaf node were selected and processed. This choice was made because the information about the type of aggregate was available for each record.

The number of papers in each A-leaf, A-branch, and A-root node was computed and named $n_{i . j . k}, n_{i . j}$ and $n_{i}$ respectively, with:

- $\quad j=1,2,3,4,5$, if $i=1$

- $\quad j=1,2$ and $k=1,2,3,4,5,6$, if $i=2$

The total amount of output data from this operation was named ' $\mathrm{N}$ '.

In the same way, the information on the other macro-clustering variables was processed. For each A-leaf node, the ID numbers of the papers were reported in rows, whereas the minimum and the maximum values of relative $\mathrm{B}-\mathrm{D}$-if they were present-were reported in columns, as shown in Figure 4 . Then, the number of not-empty cells in each column was counted, and its ratio to the corresponding $n_{i . j . k}$ was computed.

The ratios were finally used to compare the formulation and the testing procedures of the collected mortars across each A-leaf node. In S1, the numerical or textual values of the variables were not considered; only their presence or lack thereof were processed to compute the aforementioned ratios. Moreover, the operations on the number of notempty cells enabled us to extend the evaluations to A-branch and root nodes, and to the whole dataset.

In the second sequence-S2-the field of use of mortars was chosen as the driving parameter. On the basis of the distinction between masonry and rendering mortars, the UNI EN 998-1,2:2016 specifications were used to group the dataset records. Five categories of masonry mortars are indicated in UNI EN 998-2:2016, depending on their 28-day compressive strength. As regards rendering mortars, UNI EN 998-1:2016 indicates six types of them, depending on their 28-day compressive strength, capillary water adsorption, dry bulk density, permeability to water under pressure, vapor permeability, and thermal conductivity. 


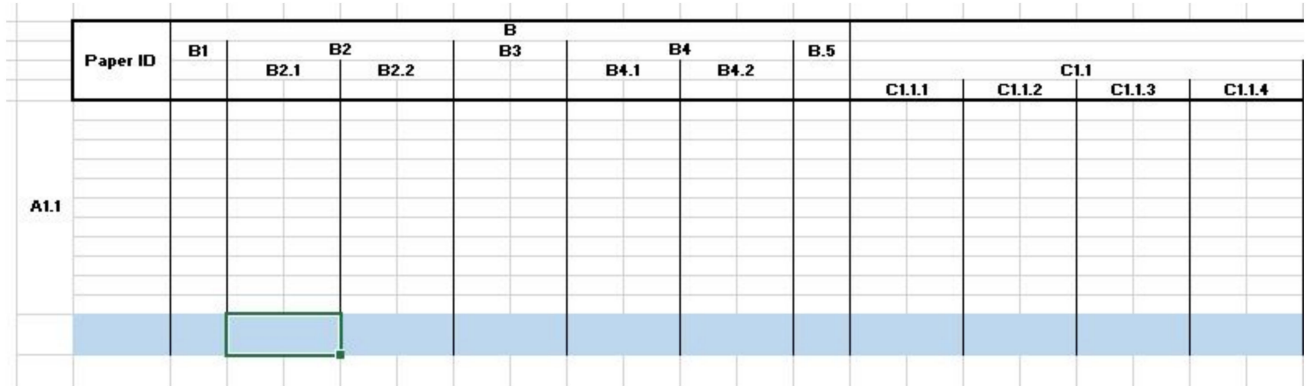

Figure 4. S1 sequence database. An extract of the Excel sheet about the A-leaf node 'A1.1' is shown. The ID numbers of the papers are reported in rows; the corresponding B, C, D values are reported in columns. The number of not-empty cells in each column is reported in the blue-colored row.

The dataset papers were classified by both normative specifications, and the number of records in each mortar class was computed. Tables 1 and 2 report the UNI EN 998-1:2016 and UNI EN 998-2:2016 specifications and the corresponding types of mortar.

Table 1. UNI EN 998-1:2016 specifications for rendering mortars. The mortar classes and relative performances ${ }^{1}$ are reported.

\begin{tabular}{|c|c|c|c|c|c|c|}
\hline Mortar Class $^{2}$ & $\begin{array}{c}\mathbf{f}_{\mathrm{c}} \\
\mathbf{M P a}\end{array}$ & $\begin{array}{c}\mathrm{W} \\
\mathrm{kg} / \mathrm{m}^{2} \min ^{0.5}\end{array}$ & $\begin{array}{c}\mathrm{d}_{\mathrm{dry}} \\
\mathrm{kg} / \mathrm{m}^{3}\end{array}$ & $\underset{\mathrm{mL} / \mathrm{cm}^{2}}{\mathrm{p}}$ & m & $\begin{array}{c}1 \\
\mathrm{~W} / \mathrm{mK}\end{array}$ \\
\hline GP & CSI to CSIV & $W_{0}$ to $W_{2}$ & & & & \\
\hline LW & CSI to CSIII & $W_{0}$ to $W_{2}$ & $<1300$ & & & \\
\hline CR & CSI to CSIV & $\mathrm{W}_{0}$ to $\mathrm{W}_{2}$ & & & & \\
\hline OC & CSI to CSIV & $\mathrm{W}_{1}$ and $\mathrm{W}_{2}$ & & $<1$ & & \\
\hline $\mathrm{R}$ & CSII & $>0.3 \mathrm{~kg} / \mathrm{m}^{2}$ after $24 \mathrm{~h}$ & & & $<15$ & \\
\hline $\mathrm{T} 1$ & CSI to CSII & $\mathrm{W}_{1}$ & & & $<15$ & $<0.10$ \\
\hline $\mathrm{T} 2$ & CSI to CSII & $\mathrm{W}_{1}$ & & & $<15$ & $<0.20$ \\
\hline
\end{tabular}

${ }^{1} \mathrm{f}_{\mathrm{C}}=28$-day compressive strength; $\mathrm{W}=$ water capillary adsorption coefficiency; $\mathrm{d}_{\text {dry }}=$ dry bulk density; $\mathrm{p}=$ permeability to water under pressure; $\mathrm{m}=$ vapour permeability coefficiency; $1=$ thermal conductivity ${ }^{2} \mathrm{GP}=$ general purposes; $\mathrm{LW}=$ lightweight $\mathrm{mortar} ; \mathrm{CR}=\mathrm{colored}$ mortar; $\mathrm{OC}=$ one coat for external use; $\mathrm{R}=$ renovation works; $\mathrm{T}=$ thermal mortars.

Table 2. UNI EN 998-2:2016 specifications for masonry mortars. The mortar classes and relative performances are reported ${ }^{1}$.

\begin{tabular}{cc}
\hline Mortar Class & $\begin{array}{c}\mathbf{f}_{\mathbf{c}} \mathbf{1}^{\mathbf{M}} \\
\text { MPa }\end{array}$ \\
\hline M1 & 1 \\
M2.5 & 2.5 \\
M5 & 5 \\
M10 & 10 \\
M15 & 15 \\
M20 & 20 \\
\hline
\end{tabular}

${ }^{1}$ 28-day compressive strength.

\section{Results}

The results are presented with the following sequence: searching, screening, and summarizing.

\subsection{Searching}

The number of records from the search queries "recycled AND aggregate", "recycled AND mortar", "recycled AND aggregate AND conglomerate", "recycled AND aggregate AND mortar", and "recycled AND aggregate AND mortar NOT concrete" was 39,991, $11,857,581,5560$, and 1345 , respectively. The addition of the Boolean operator "NOT" to the query "recycled AND aggregate AND mortar" reduced the search records by about $76 \%$. This filter was used-as explained in Section 2.1— to exclude the concretes because 
they were beyond the field of interest. However, the filter was not appropriate because it omitted the papers about mortars with RA originating from the recycling of concretes, which were of great interest.

The search records were then sorted by their year of publication, and an exponential growing trend was generally found, as is shown in Figure 5. "Recycled AND aggregate AND mortar" exhibited the highest growth change (+1105\%), followed by "recycled AND mortar" (+685\%), "recycled AND aggregate AND mortar NOT concrete" $(+625 \%)$, "recycled AND aggregate AND conglomerate" (+456\%), and "recycled AND aggregate" (+433\%).

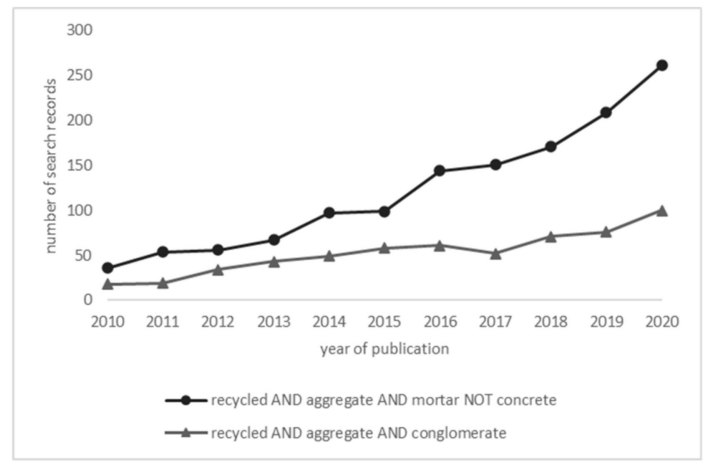

(a)

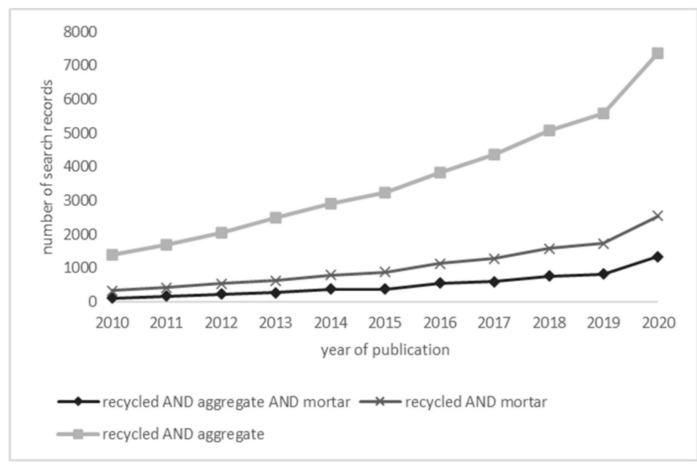

(b)

Figure 5. Trends of the search records within the time interval 2010-2020. The number of records is plotted against the year of publication: (a) "recycled AND aggregate AND mortar NOT concrete", "recycled AND aggregate AND conglomerate"; (b) "recycled AND aggregate AND mortar", "recycled AND mortar", "recycled AND aggregate".

In the second stage of the bibliometric search, the addition of filters and the shortened time interval resulted in a far smaller number of records: "recycled AND aggregate AND mortar AND TITLE mortar" numbered 543, and "recycled AND aggregate AND rendering AND TITLE rendering" numbered 10. Finally, the records from the query "recycled AND aggregate AND conglomerate" with the time interval 2015-2020 numbered 418.

\subsection{Screening}

The screening phase was conducted on this analysis dataset:

- recycled AND aggregate AND mortar AND TITLE mortar: 543 records,

- recycled AND aggregate AND rendering AND TITLE rendering: 10 records,

- recycled AND aggregate AND conglomerate: 418 records,

with a total number of 971 . On the basis of the Prisma flow diagram, eight duplicates and 30 unpublished papers were excluded. The elimination of the RA applications which were barely related to this study-according to the criteria presented in Section 2.2resulted in the following eligible records:

- recycled AND aggregate AND mortar AND TITLE mortar: 93 records,

- recycled AND aggregate AND rendering AND TITLE rendering: 3 records,

- $\quad$ recycled AND aggregate AND conglomerate: 8 records.

Many of the records focused on the use of RA for the stabilization of soils, asphalt and road constructions and concretes; hence, they were not suitable for this review. The final dataset consisted of 104 records.

\subsection{Summarizing}

After the Excel database was created and the data were entered, some preliminary analyses were performed by processing the data about binders. One hundred and twenty three inputs were found-because some mixes employed blended binders-and the cement and the lime were the most and the least frequent ones, respectively. In fact, cement was counted 104 times, and the hydrated and the hydraulic lime three and two times, 
respectively. The other binders mostly included steel factory by-products—such as ground granulated blast furnace slag and fly ash-and were counted 14 times.

With respect to the terminology employed in the Section 2.4, the following two subsections report the results of the summarizing sequences S1 and S2.

\subsubsection{S1 Sequence}

As regards the data about the type of RA, 137 values were counted, because in some papers more than one type of RA was used. The RA were sourced from C\&D (A1) for about $45 \%$, and from factories and recycling centers (A2) for about $55 \%$. In A2, $64 \%$ originated from recycling centers (A2.2), and only $36 \%$ from building materials factories (A2.1). In the whole analysis dataset, plastic $(23 \%)$, ceramics $(18 \%)$, and cementitious materials $(17 \%)$ were the most popular source materials, whereas natural ( $2 \%)$, stone $(4 \%)$ and mineral $(5 \%)$ were the least popular ones, as shown in Figure 6.

\section{RA source materials}

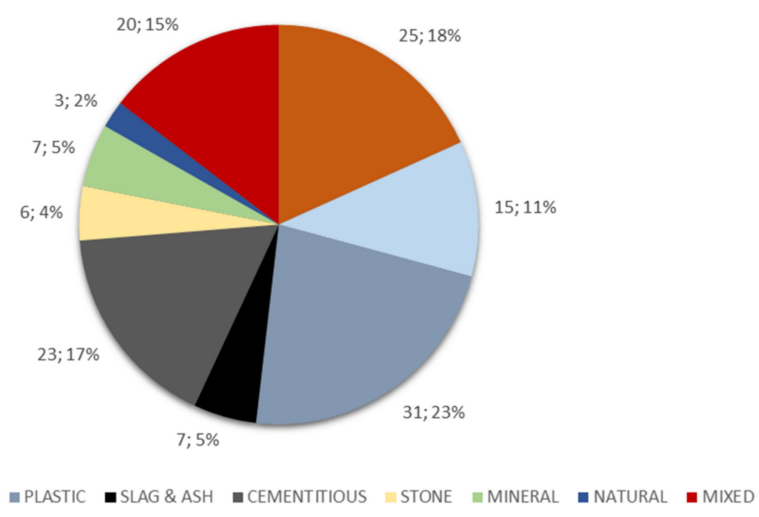

Figure 6. Distribution of RA source materials within the analysis dataset. The number of counts and the percentage of each category are shown.

The distribution of the source materials was also processed for A1, A2.1, and A2.2 separately, as shown in Figure 7. The ceramics exhibited a regular trend, whereas the other materials were unequally distributed. No plastic aggregates originated from $C \& D$, and no glass aggregates came from building materials factories. The cementitious materials were always sourced from $C \& D$, except for one case from building materials factories.

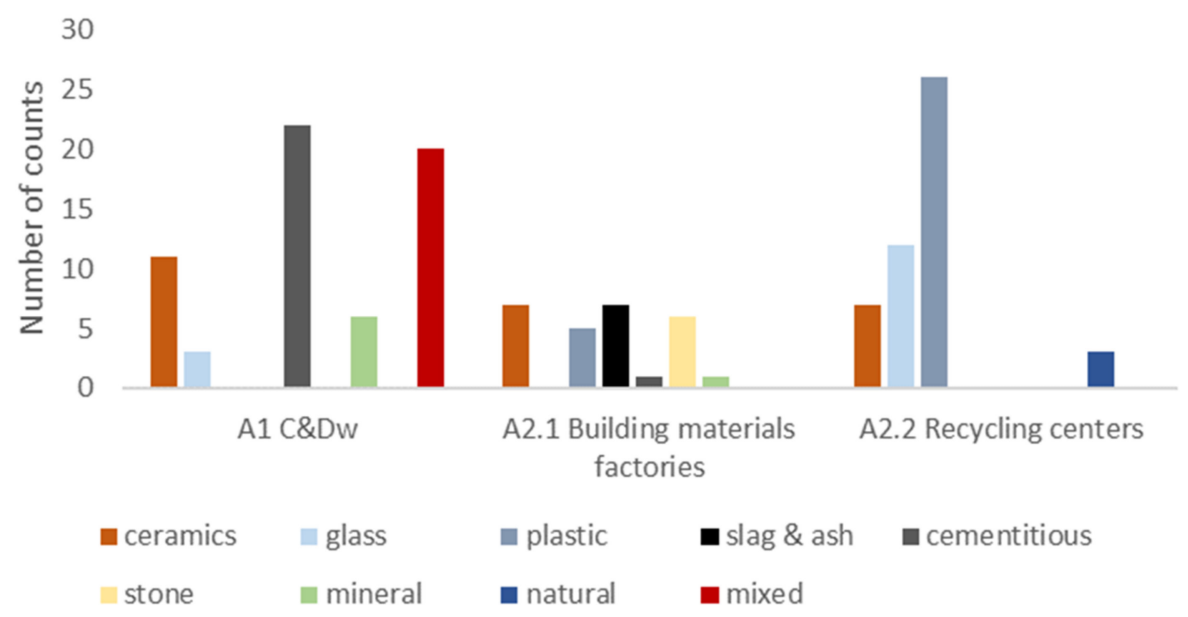

Figure 7. Distribution of the RA source materials in the A1, A2.1 and A2.2 branch nodes. The number of counts of each material is shown. 
The ni.j.k, ni.j, and ni values are reported in Figure 8. As was already mentioned, the papers were counted more than once if they contained more than one type of aggregate.

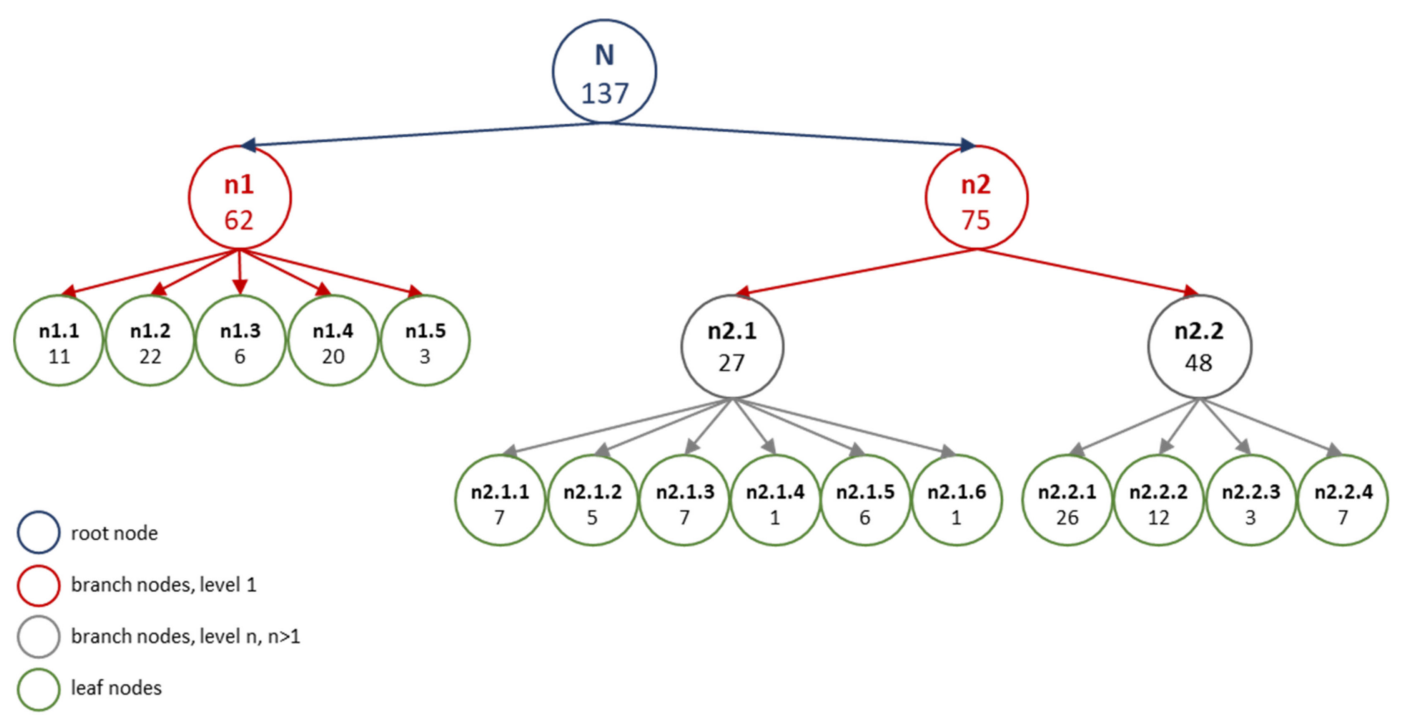

Figure 8. Distribution of RA based on the 'A-type of aggregate' variable. The number of papers in each node is reported.

Some evaluations were performed before the ratios for the $B, C$, and D variables were computed. B1 'number of mixes' was excluded from the analysis because it was not useful for the summarizing operations; in fact, the S1-sequence does not deal with the numerical values of variables, but rather considers the number of times a variable was measured. Because the number of mixes was always specified, it was an ineffective data. For the same reason, the variables which expressed the same property in different units of measurement were aggregated as follows:

- $\quad \mathrm{C} 1.2 .4, \mathrm{C} 1.2 .5, \mathrm{C} 1.2 .6$ and $\mathrm{C} 1.2 .7$, because they measured the capillary water adsorption.

- C3.1 and C3.2, because they measured the chloride ion penetration.

- $\quad$ C3.10.1 and C3.10.2, because they measured the drying shrinkage.

The ratios of the variables B, C, and D were plotted in clustered bar charts in order to highlight two complementary aspects, quantitative and qualitative, respectively. The height of the bars gives information about the size distribution of the ratios depending on the A-leaf node, i.e., given the A-leaf node, the number of papers in which the variable was collected to the total number of papers of that A-leaf node. The density of the bars-the variety of colors-underlined the most- and the least-analysed variables, i.e., the number of A-leaf nodes in which the variable was collected out of the total number of A-leaf nodes. This means that the height and the density of the bars are not directly proportional. The color palette consists of 15 units which correspond to the RA categories, i.e., the A-leaf nodes.

Figures 9-12 report some extracts from the graph in order to facilitate its understanding, whereas the whole chart is shown in Figure A4. 


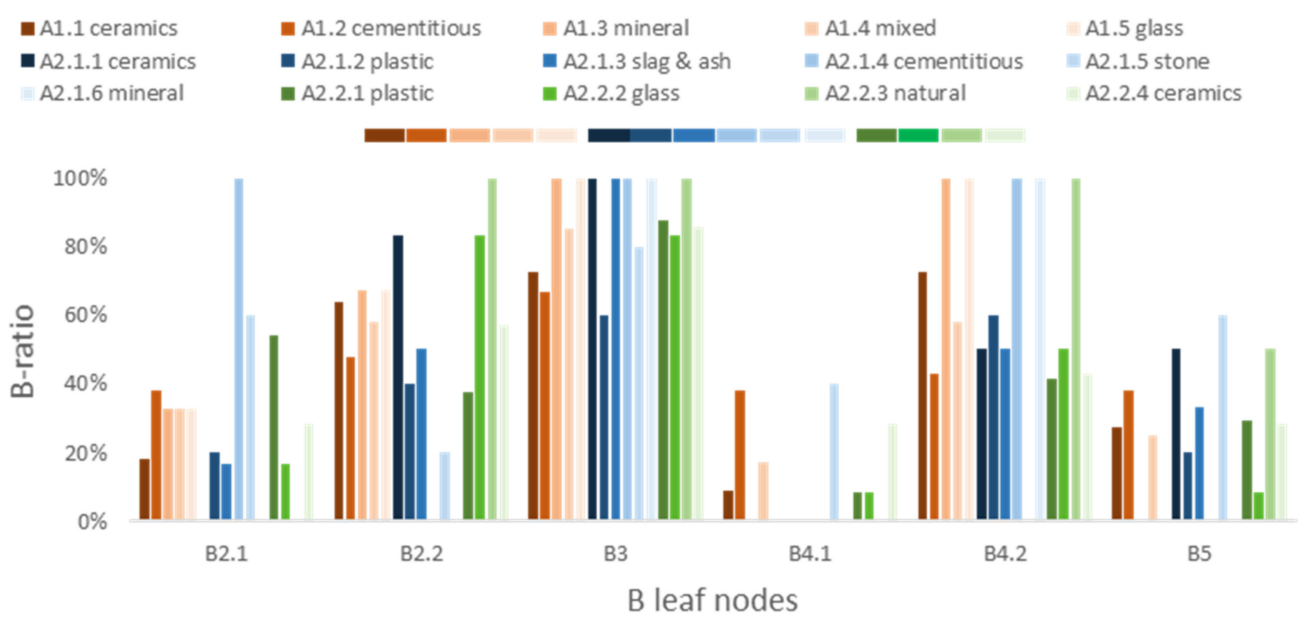

Figure 9. B-ratio of the B leaf nodes. The clustered bar chart plots the values of the B-ratio of the corresponding B leaf nodes.

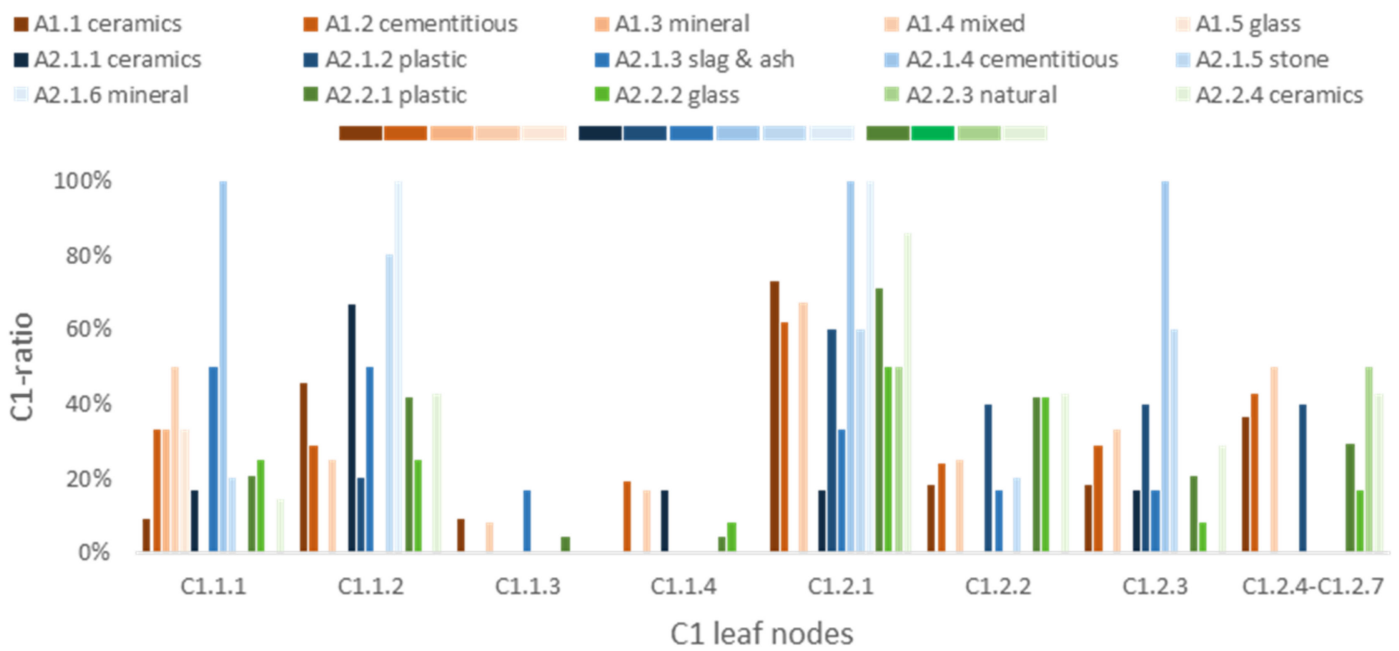

Figure 10. C1-ratio of the $\mathrm{C} 1$ leaf nodes. The clustered bar chart plots the values of the C1-ratio of the corresponding $\mathrm{C} 1$ leaf nodes.

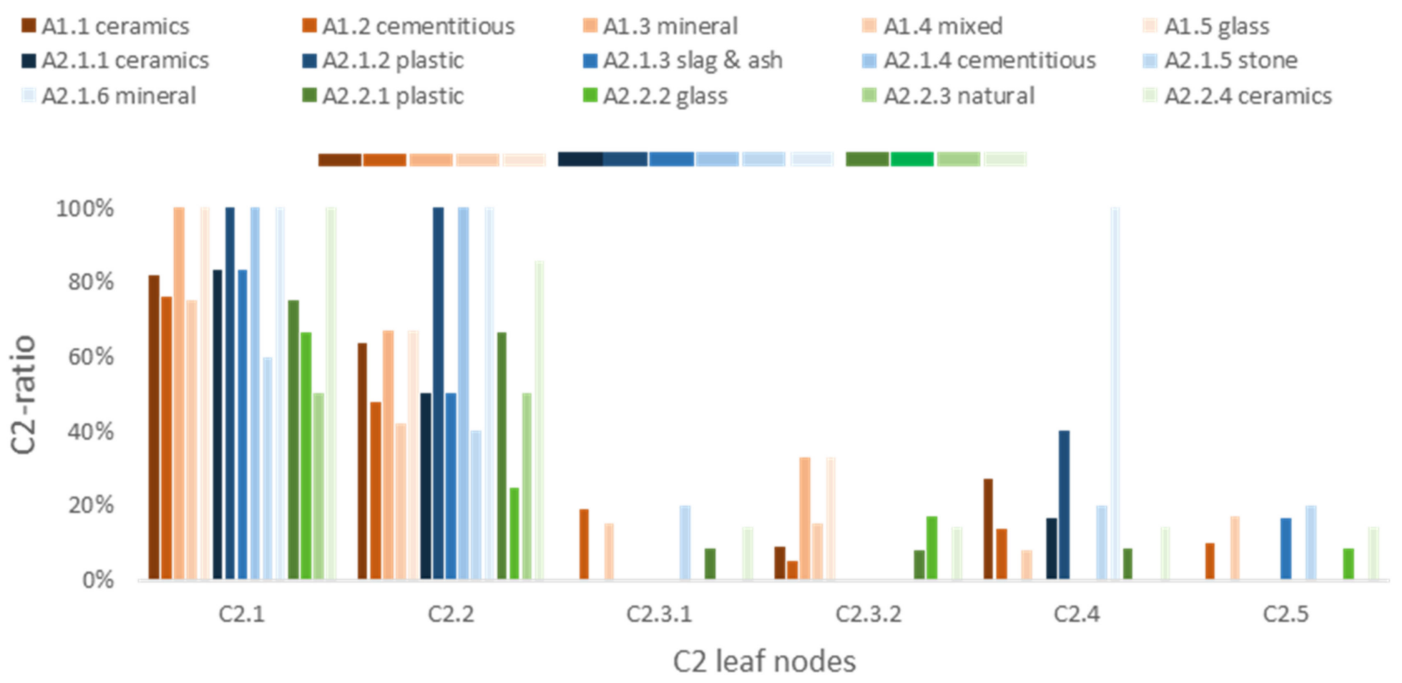

Figure 11. C2-ratio of the $\mathrm{C} 2$ leaf nodes. The clustered bar chart plots the values of the C2-ratio of the corresponding $\mathrm{C} 2$ leaf nodes. 


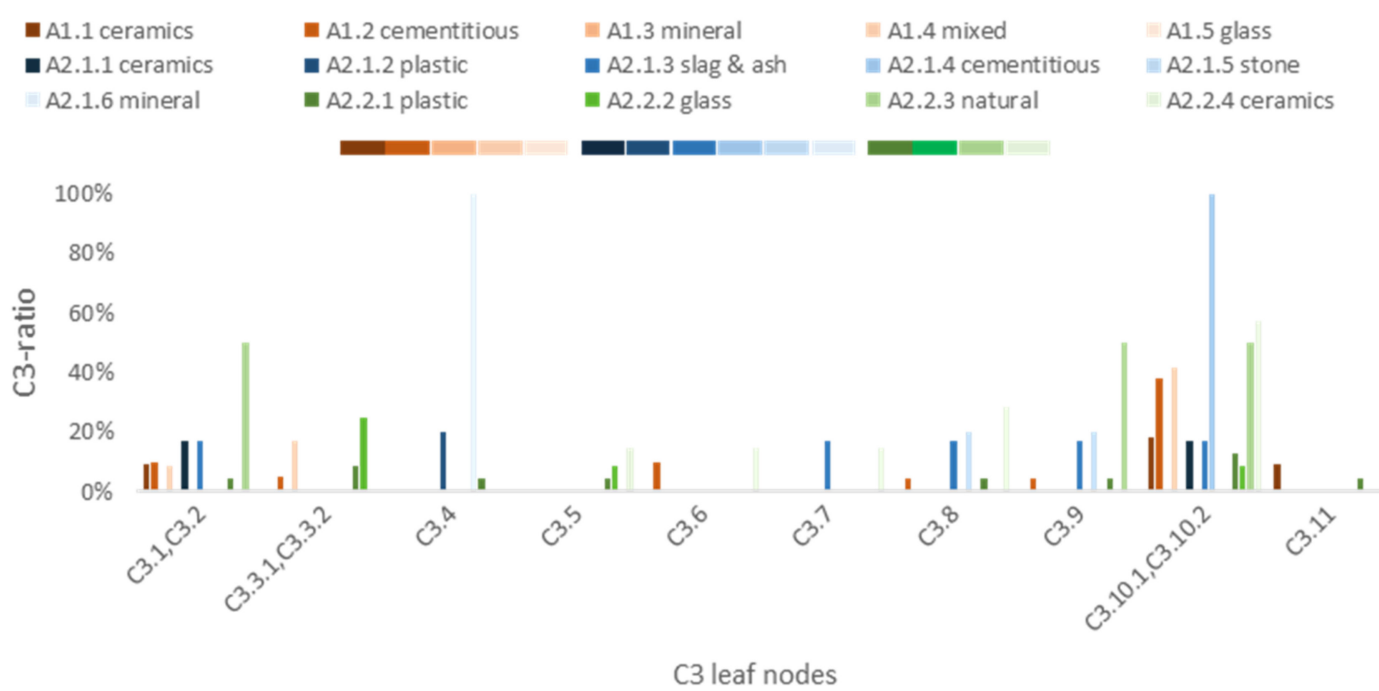

Figure 12. C3-ratio of the C3 leaf nodes. The clustered bar chart plots the values of the C3-ratio of the corresponding C3 leaf nodes.

As shown in Figure 9, the B-ratio was generally a high number, with a mean value of $46 \%$. As regards the density of the bars, the most frequent information was about the water to binder ratio (B3) - which covered all of the RA categories - followed by the RA to NA ratio (B2) and the aggregates to binder ratio (B4). In the last two cases, the value was expressed more frequently by mass than by volume: the B2.2 and B4.2 bars were higher and more dense than the B2.1 and B4.1 bars; in fact, the aggregate to binder ratio by volume (B4.1) was used only in 20 out of the 137 data points.

Among the $\mathrm{C} 1$ variables-except for viscosity $(\mathrm{C} 1.1 .3)$ and air content (C1.1.4) - the physical properties were frequently measured for all of the RA. The most dense $\mathrm{C} 1$ variables were the fresh-state properties bulk density (C1.1.1) and slump value (C1.1.2), and the hard-state properties bulk density (C1.2.1), porosity (C1.2.2), and water adsorption by total immersion (C1.2.3). The C1.2.1 ratios were, on average, $64 \%$; this means that the bulk density was measured for nearly all of the papers of each A-leaf node, and for nearly all of the A-leaf nodes (dense and high bars). On the contrary, C1.1.1, C1.1.2, C1.2.2 and C1.2.3 were measured for nearly all of the A-leaf nodes, but their ratios were on average $27 \%$, $40 \%, 21 \%$, and $29 \%$, respectively (dense and low bars). The water adsorption by capillarity (C1.2.4 to C1.2.7) was measured in one out of 27 of the data points from building material factories (A2.1), whereas it was measured in all of the categories of recycling centers (A2.2), with an average ratio of $35 \%$, and in three out of five categories of C\&D (A1.1), with an average ratio of $43 \%$. The $\mathrm{C} 1$ chart is reported in Figure 10.

An irregular trend was found among the mechanical properties (C2), as shown in Figure 11. The compressive and flexural strength (C2.1 and C2.2, respectively) were the densest and highest variables because they were measured for all of the A-leaf nodes (variety of colors), with an average value of $83 \%$ for C2.1 and 64\% for C2.2. Compressive strength-in particular-was frequently examined in the A1 and A2.1 classes, with average values of $87 \%$ and $88 \%$, respectively. On the contrary, the other mechanical properties were rarely computed: the mean values of the 28-day and 90-day elastic modulus (C2.3.1 and C2.3.2), 28-day bonding strength (C2.4), and 28-day adherence (C2.5) were 5\%, $17 \%, 19 \%$, and $7 \%$, respectively.

The C 3 and C4 variables-related to durability and thermal-hygrometric propertiesexhibited a low ratio and a low density of their bars. As shown in Figures 12 and 13, the bars are scattered, and few colors of the available range are present. The $\mathrm{C} 3$ ratios were, on average, lower than $10 \%$, with the minimum value of $2 \%$ for the accelerated ageing test of their heat-freeze and freeze-thaw cycles (C3.5), and for the permeability under water pressure test (C3.6). The only exception in C3 was the 28-day drying shrinkage (C3.10.1 
and C3.10.2), with 28 data points out of 137, 10 A-leaf nodes out of 15, and a mean ratio of $26 \%$.

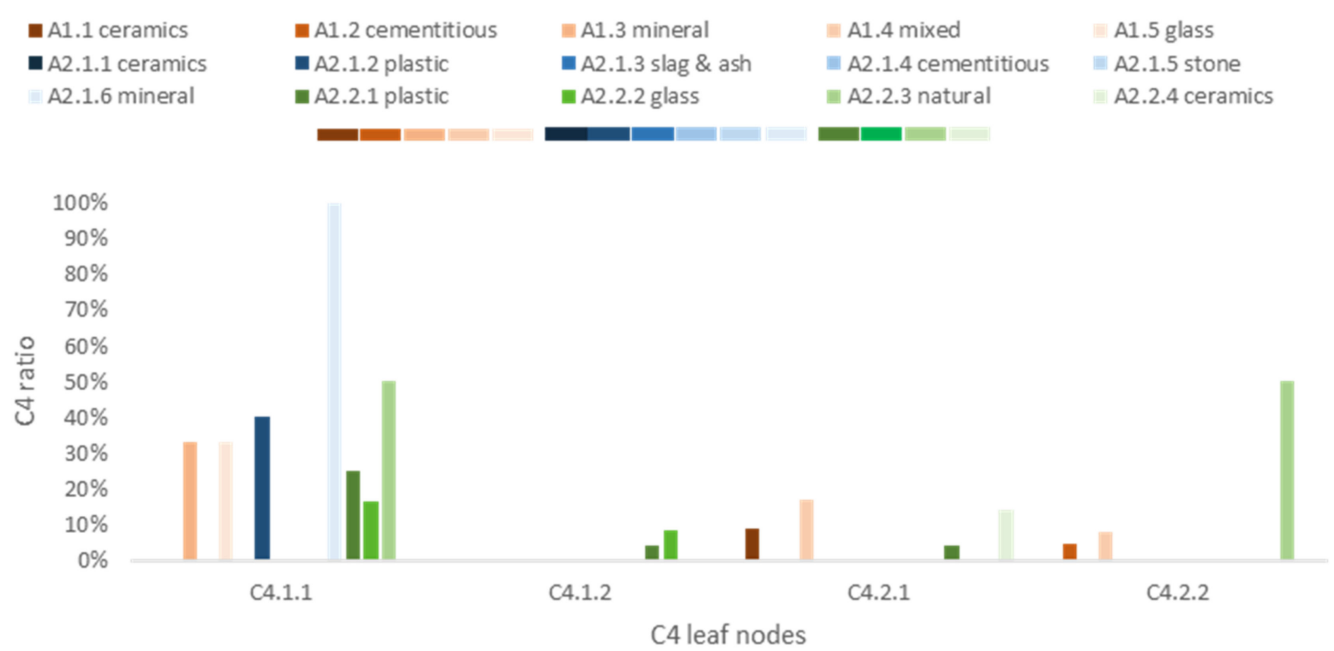

Figure 13. C4-ratio of the C4 leaf nodes. The clustered bar chart plots the values of the C4-ratio of the corresponding C4 leaf nodes.

Among the thermal and hygrometric properties, thermal conductivity (C4.1.1) exhibited the densest and highest bars, with 14 data points out of 137, seven A-leaf nodes out of 15 , and a mean ratio of $25 \%$. The RA from recycling centers were the most covered, with nine data points out of the aforementioned 14 , followed by building material factories, with three data points out of 14 , and by $C \& D$, with two data points out of 14 . With reference to the corresponding A-branch node, $\mathrm{C} \& \mathrm{D}$ were the least covered (two data points out of the total 62 records from $\mathrm{A} 1)$.

The other variables, thermal diffusivity (C4.1.2), vapor permeability (C4.2.1), and resistance to vapor permeability (C4.2.2), showed $1 \%, 4 \%$, and $5 \%$ ratios, respectively. The results are shown in Figure 13.

The chemical and mineralogical properties (C5) followed an irregular trend, as shown in Figure 14. From C5.1 to C5.4, the mean ratio of $15 \%$ was observed, with the maximum value of $31 \%$ for the SEM analysis (C5.3), and the minimum value of $8 \%$ for TGA (C5.2) and Leaching test (C5.4), whereas for the $\mathrm{pH}$ test and $\mathrm{XRF}$ (C5.5 and C5.6) the ratio was on average $1 \%$. C5.3 covered 13 A-leaf nodes out of 15 , and 33 data points out of 137 , among which 16 data points were from C\&D.

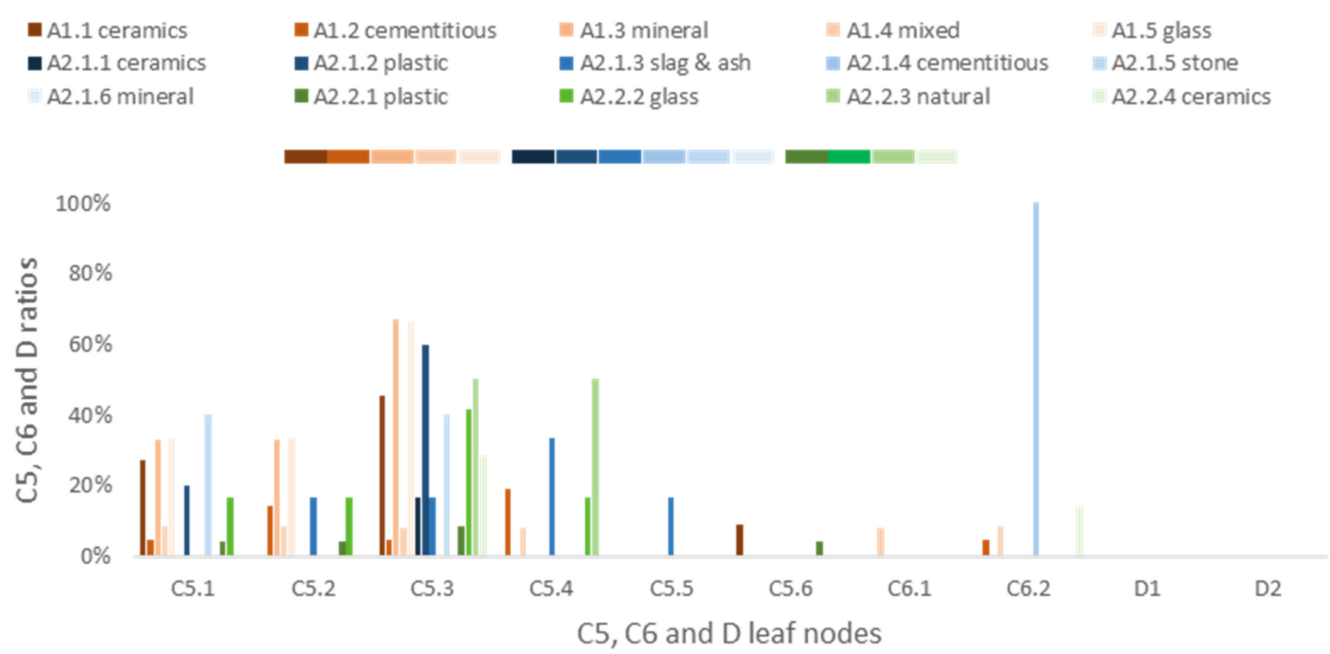

Figure 14. C5, C6 and D-ratios of the C5, C6 and D leaf nodes. The clustered bar chart plots the values of C5 and C6, and the D-ratio of the corresponding C5, C6 and D leaf nodes. 
Only two and three data points out of 137 were about LCA (C6.1) and economic viability (C6.2), respectively, and no data were found about patents or other types of intellectual property protection (D1), or the availability of the tested mixes on the market (D2).

The mean ratios across the A-branch nodes-A1, A2.1 and A2.2-were then plotted separately in order to further analyze the outcomes of the presented charts. As shown in Figure 15, RA from building material factories and recycling centers covered almost all of B, C, and D variables-41 and 42 out of 44 , respectively - but their ratios were, on average, lower than the C\&D ones. The values were $20 \%$ for A2.1 and A2.2, and $25 \%$ for A1. In addition, the data on RA from recycling centers included nearly all of the durability (C3) and thermal-hygrometric (C4) properties which were omitted in the other two classes, instead.

In the end, the number of counts of each $B, C$, and D leaf node compared to the total number of data $(\mathrm{N})$ was computed and was named the N-ratio. As reported in Figure 16, the mix proportions (B) and physical properties (C1) were the most frequent variables across the whole dataset, whereas $\mathrm{C} 3$ and $\mathrm{C} 4$ were the less-common ones. $\mathrm{C} 2$ and $\mathrm{C} 5$ confirmed their irregular trends, because some of these variables resulted in high ratios-e.g., C2.1, C2.2, C5.3-and others resulted in low ratios.

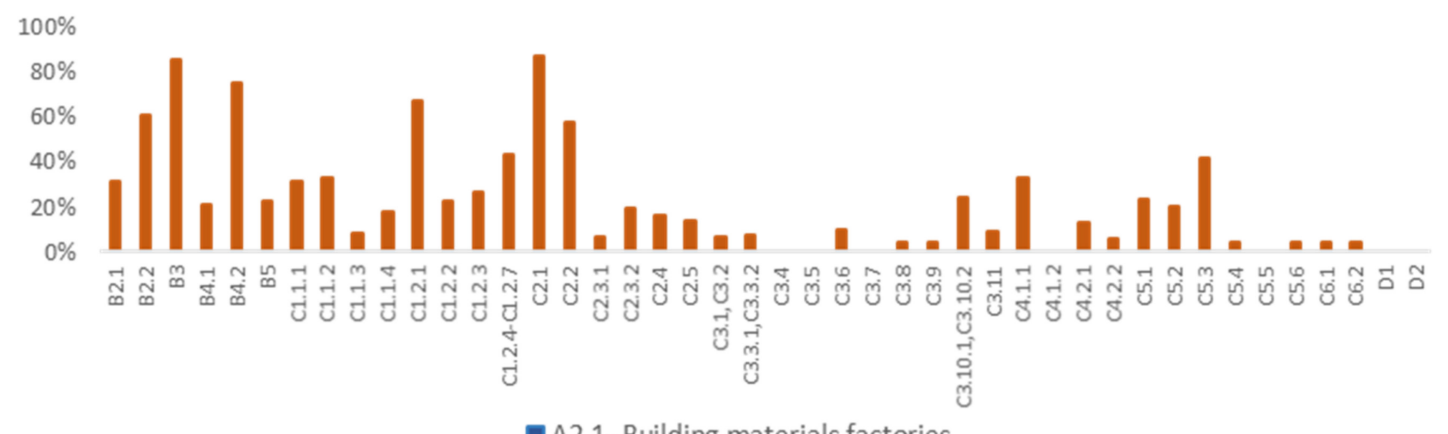

A2.1- Building materials factories

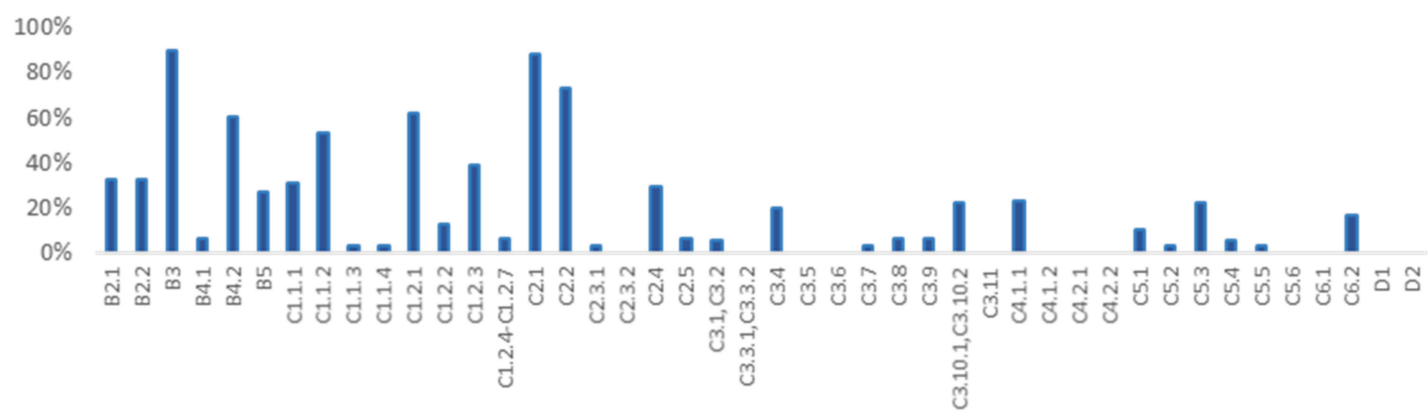

A2.2 - Recycling centers

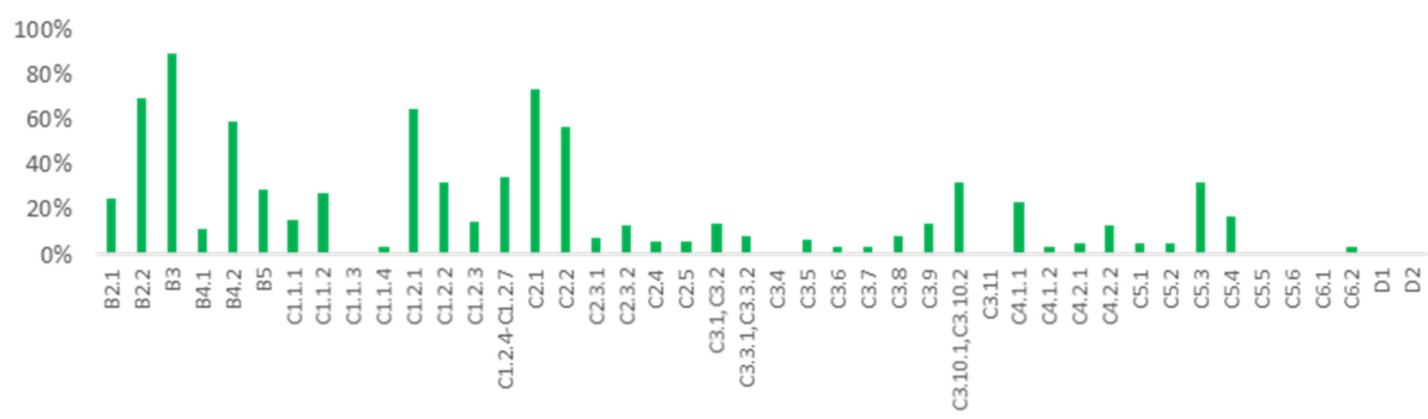

Figure 15. B, C, and D ratios of the B, C, and D leaf nodes for the A1, A2.1, and A2.2 branch nodes. The clustered bar chart plots the values of the $\mathrm{B}, \mathrm{C}$ and $\mathrm{D}$ ratios of the corresponding $\mathrm{B}, \mathrm{C}$, and $\mathrm{D}$ leaf nodes. 


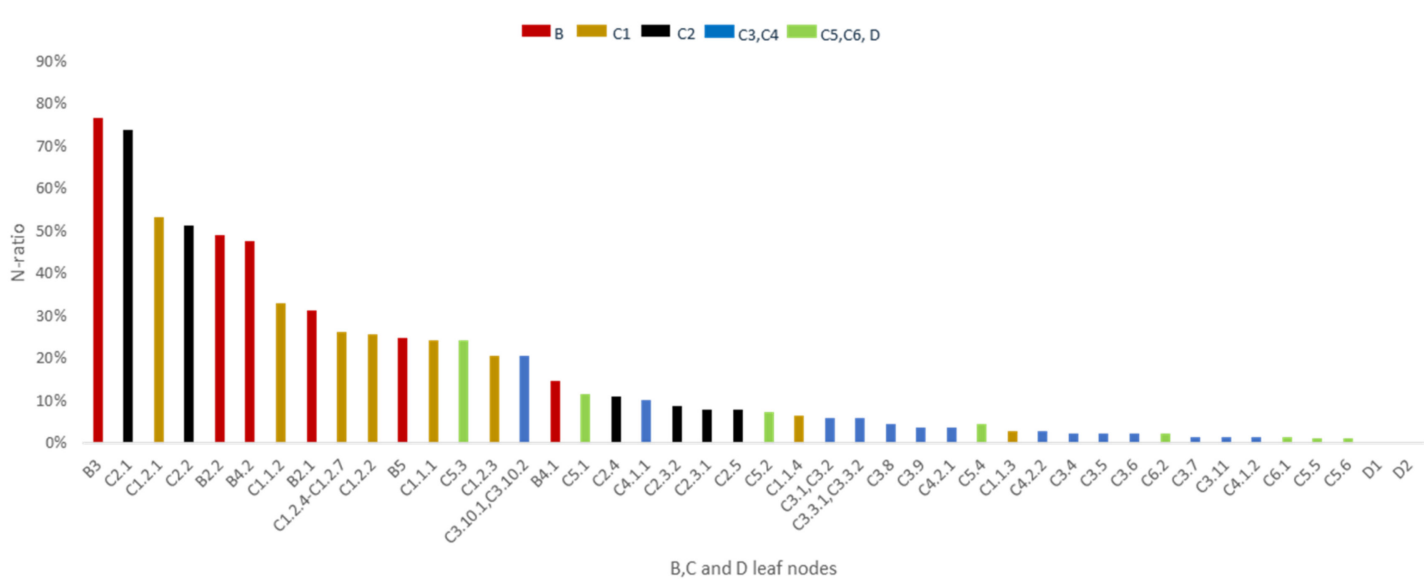

Figure 16. N-ratios of the B, C, and D leaf nodes. The N-ratio is the number of counts of each B, C, and D leaf node to the total number of data points (137). The clustered bar chart plots the values of the N-ratios of the corresponding B, C, and D leaf nodes. The ratios are sorted in decreasing order.

Supplementary graphs-Figures A5-A8-were plotted to compare the materialssuch as ceramics, cementitious materials, plastic, and glass-which were in common to the different RA sources. The outcomes confirmed that the hard-state physical properties and the mechanical properties were the most frequent variables. No thermal and hygrometric properties were computed for the cementitious RA-both from C\&D and building material factories-and few analyses on the durability were performed across all of the aforementioned source materials. The list of the collected papers with their relative ID numbers, A-leaf nodes, and reference numbers is reported in Figure A9.

\subsubsection{S2 Sequence}

Moving on from the UNI EN 998-1:2016 specifications for rendering mortars, the collected papers were filtered on the basis of:

- 28-day compressive strength: C2.1,

- $\quad$ water adsorption by capillarity: C1.2.4-C1.2.7,

- dry bulk density: C1.2.1,

- permeability to water under pressure: C3.6,

- resistance to vapor permeability: C4.2.2,

- thermal conductivity: C4.1.1.

As regards the compressive strength, eight records were found in CS I, 22 in CS II, 30 in CS III, and 77 in CS IV. The filter on C1.2.4-C1.2.7 resulted in eight records for W1 and six records for W2; W0 was not considered, because it corresponds to 'no declared value'. Only five records were suitable for the regulatory indications about the bulk density, and one record was suitable for the permeability to water under pressure. In fact, the collected mortars were generally heavyweight mortars, and their dry bulk density was on average $1798 \mathrm{~kg} / \mathrm{m}^{3}$, which is higher than the normative threshold of $1300 \mathrm{~kg} / \mathrm{m}^{3}$ for lightweight mortars. In regard to the thermal-hygrometric performances, five records were suitable both for C4.2.2 and C4.1.1.

The combination of the abovementioned specifications-reported in Table 1—resulted in the classification of the collected RA mortars for rendering purposes. No records were appropriate for the one coat external use category (OC): C3.6 was lower than $1 \mathrm{~mL} / \mathrm{cm}^{2}$ only in one paper, but its water adsorption by capillarity was much higher than the regulatory limit. Moreover, only one record was classified as thermal mortar because, in the other two cases, there was no information about C4.2.2 and C1.2.4-C1.2.7.

The general purpose, lightweight mortars, and colored renderings were counted six, four, and six times, respectively. Table 3 reports the paper ID for each category of rendering mortars. 
Table 3. Rendering mortars according to the UNI EN 998-1:2016 specifications. The paper IDs which were suitable for the normative indications are reported; the title of the papers is reported in Figure A9.

\begin{tabular}{cccccc}
\hline $\mathbf{G P}^{\mathbf{1}}$ & $\mathbf{L W}^{\mathbf{1}}$ & $\mathbf{C R}^{\mathbf{1}}$ & $\mathbf{O C}^{\mathbf{1}}$ & $\mathbf{R}^{\mathbf{1}}$ & $\mathbf{T}^{\mathbf{1}}$ \\
\hline 8 & 5 & 8 & & 8 & 8 \\
26 & 22 & 26 & & 98 & \\
39 & 29 & 39 & & & \\
49 & 83 & 49 & & & \\
60 & & 60 & & & \\
96 & & 96 & & \\
\hline
\end{tabular}

${ }^{1}$ The acronyms referred to the UNI EN 998-1:2016 classifications.

Three lightweight mortars (LW) out of four-paper IDs 5, 22 and 29-were formulated with plastic RA from building material factories (A2.1.2), and three general purpose (GP) and colored mortars (CR) were sourced from plastic RA from recycling centers (A2.2.1): paper IDs 26, 39 and 49.

The relation between the RA source material and the classes of the papers is shown in Figure 17.

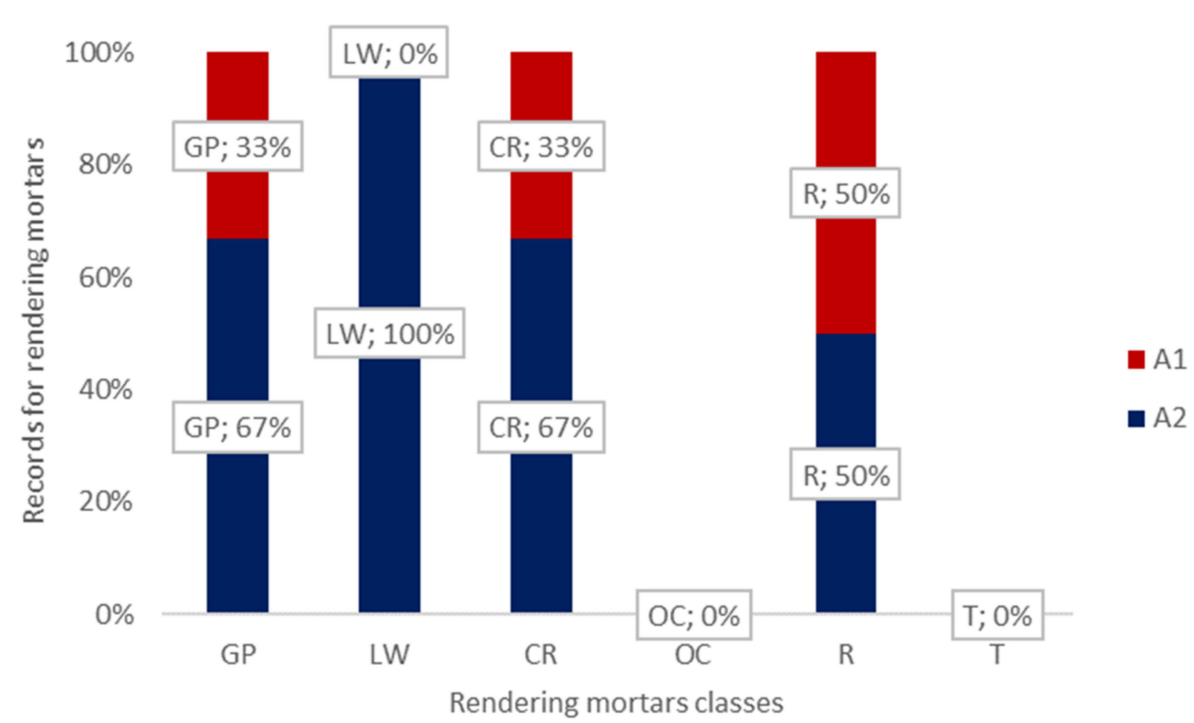

Figure 17. Collected rendering mortars according to the UNI EN 998-1:2016 specifications. For each class of rendering mortars, the papers were qualified by their source materials.

Figure 17 underlines that the collected rendering mortars were mainly formulated with RA from building material factories or recycling centers; the lightweight mortars-in particular-contained A2 recycled aggregates.

The same method was used to classify the collected papers on the basis of the UNI EN 998-2:2016 specifications for masonry mortars. The number of suitable records for M1, M2,5, M5, M10, M15, and M20 mortars were 3, 6, 13, 5, 9, and 50, respectively. The prevalent class was M20, which covered more than half of the filtered papers. These papers were then qualified by their A-leaf node, in order to find any relationships between the RA type and use of mortars. The number of masonry mortar records of each A-leaf node was evaluated and decreasingly ordered, as shown in Figure 18. The most assorted class was M20, with 12 A-leaf nodes out of 15 , among which C\&D represented more papers (34 out of 62); M15, M5, and M2,5 were more equally distributed, whereas C\&D and recycling centers dominated M10 and M1, respectively. 


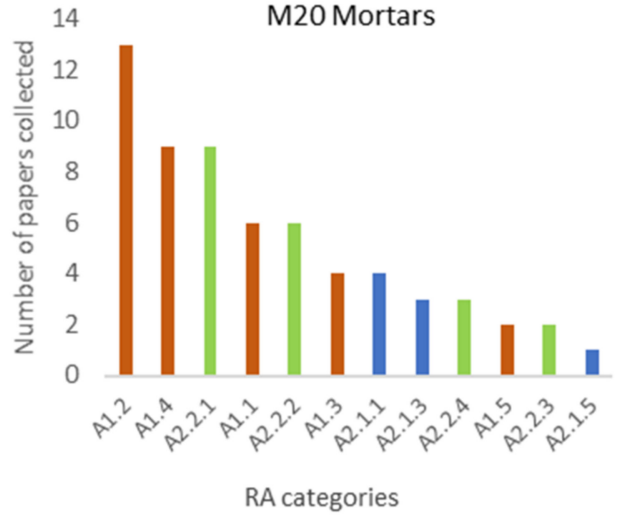

(a)

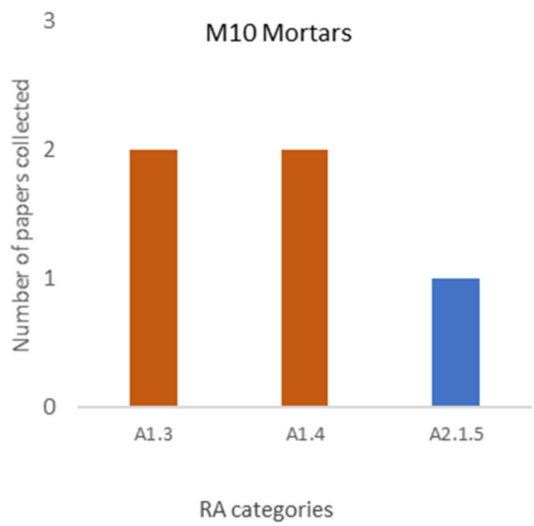

(c)

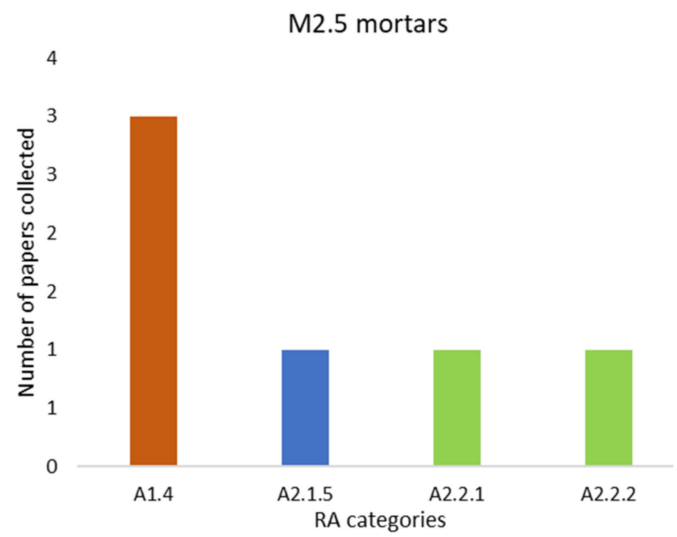

(e)

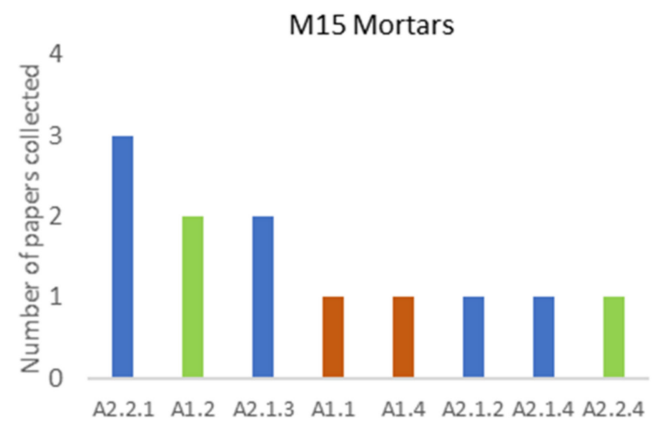

RA categories

(b)

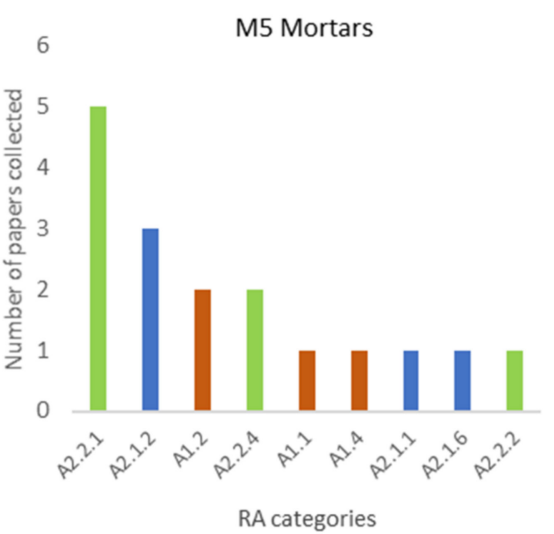

(d)

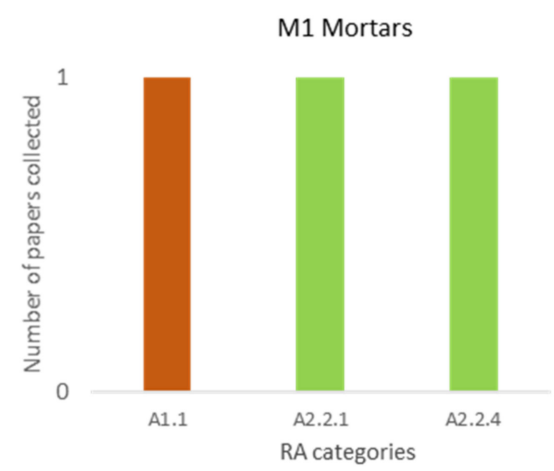

(f)

Figure 18. Collected masonry mortars according to the UNI EN 998-2:2016 specifications. The records found in each normative class were qualified by their A-leaf node, and the number in each node was computed. The figures report the computed values—decreasingly ordered-for each masonry mortar class: (a) the M20 masonry mortar class; (b) the M15 masonry mortar class; (c) M10 masonry mortars; (d) the M5 masonry mortar class; (e) the M2.5 masonry mortar class; (f) the M1 masonry mortar class.

As for the rendering mortars, the relationship between the RA source materials and the classes of the papers was evaluated, and is shown in Figure 19. The list of the collected papers with their relative ID numbers, A-leaf nodes, and reference numbers is reported in Figure A9. 


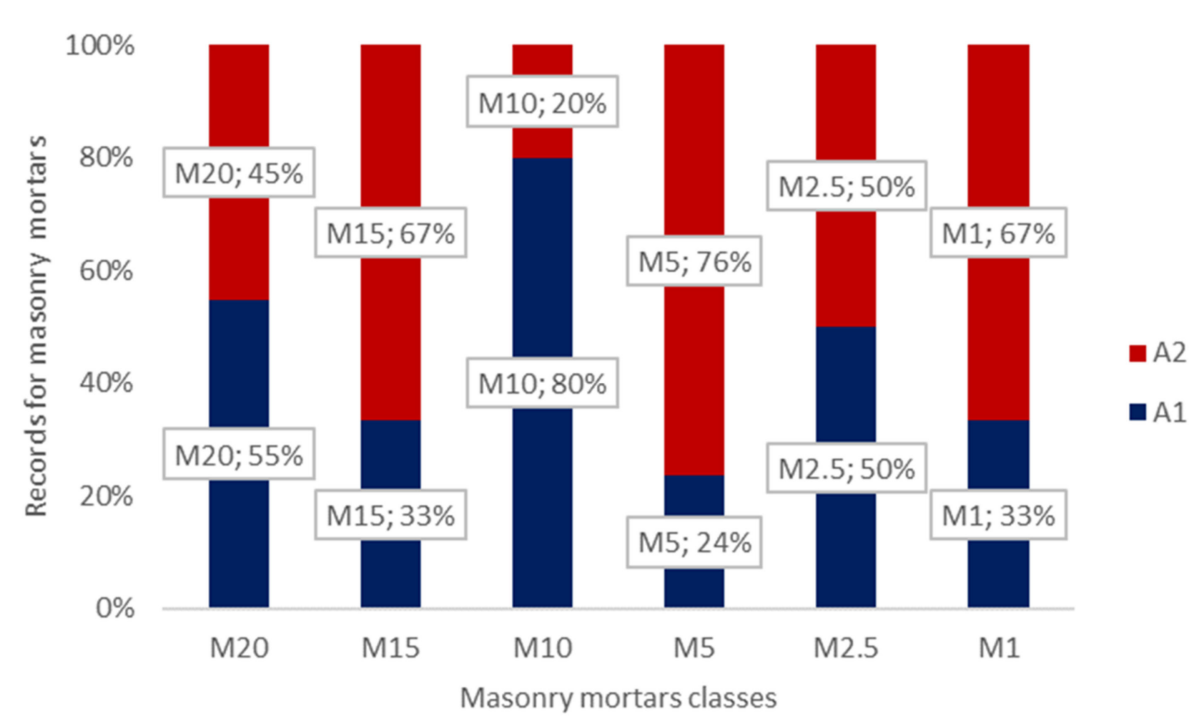

Figure 19. Collected masonry mortars according to the UNI EN 998-2:2016 specifications. For each class of masonry mortars, the papers were qualified by their source materials.

\section{Discussion and Conclusions}

The purpose of this review was to investigate the state-of-the-art of a current scientific issue - the sustainability and circular economy of building materials-with a specific focus on mortars packaged with recycled aggregates from building-related processes. The set of the analysed papers included studies about both masonry and rendering mortars, with the aim of highlighting the researchers' major and minor points of interest in terms of the types of RA and classes of mortars. The key findings and gaps are discussed in the subheadings below, and were grouped according to the three variables-from the clustering and summarizing phases of the proposed methodology - which proved to be the most significant: the types of RA, the tested properties, and the field of use of mortars; finally, a potential future research framework and conclusions are given.

\subsection{Key Findings and Gaps}

\subsubsection{Types of RA}

The analysis of the RA in the collected papers resulted in a sort of balance between the two main categories of sources, $C \& D$ and factories and recycling centers. However, if $C \& D$ and the sub-category building material factories are compared, a lack of balance appears: 62 vs. 28 papers, respectively. Because the waste from building material factories is similar to C\&D - as regards the constituent materials-it is significant that only one recycled aggregate out of five is sourced from the former, whereas almost one out of two is sourced from the latter. This result is consistent with those reported previously in other studies, which observed that demolished concrete was the major source of used RA, whereas waste from other building materials was less-often employed [11,21].

As regards the materials of the RA collected, plastic and cementitious materials were the most frequent, and were sourced, respectively, from recycling centers and C\&D. Only a few plastic (five out one hundred and thirty seven) and cementitious (one out one hundred and thirty seven) aggregates came from building material factories. This point highlights the low level of circular economy implemented in the factories of building materials. A more substantial use of industrial waste, instead, would be a successful operation, because the factories can control the characteristics of their by-products, which are otherwise variable, such as in C\&D or recycling centers, where the source is not specified [11,22-24].

\subsubsection{Tested Properties}

The S1 summarizing sequence highlighted that a consistent number of the analysed papers dealt with the physical and mechanical characterizations of RA mortars, whereas 
few works investigated the durability and thermal-hygrometric properties. The physical properties-e.g., workability - are directly linked to the suitability of the mortars at the building site; hence, it is necessary to measure them in order to verify the effective use of the conglomerates [25]. However, the physical properties are not included in the normative specifications about masonry and rendering mortars, except for their dry bulk density and water capillary adsorption coefficient, which define some classes among the rendering mortars. Despite this, water capillary adsorption was rarely measured in the analysed dataset, especially for RA from building material factories. On the other hand, the frequent investigation of compressive and flexural strength - among the mechanical properties-was found in other works [1,2], which in fact suggested extending the engineering properties of the RA conglomerates to be tested, e.g., environmental protection functions. As regards durability properties, different findings were reported in [2], but that review was mainly about RA used in concretes, of which the durability is characterized more frequently than for mortars [26-28]. Finally, very few collected papers investigated sustainability issues concerning RA mortars - as regards both environmental and economic analyses - which are key points, opting instead for the development of the tested products and their placing on the market. In fact, no analysed mortars were patented or available on the market.

\subsubsection{Field of Use of RA Mortars}

The outcomes of the S2 summarizing sequence showed that the main focus of the analysed papers was on the highest class among masonry mortars-i.e., M20, with fifty counts out of one hundred and thirty seven-whereas only eleven out one hundred and thirty seven records were suitable for rendering applications. This result is consistent with the key findings and gaps presented in Sections 4.1.1 and 4.1.2, because the aspects 'mix design-performances-field of use' are mutually related. In fact, if the experimental campaign aims to investigate the feasibility of RA to substitute NA in masonry applications, the formulation of the mortars is oriented to assure high mechanical performances. In this case, the RA are chosen from among ceramics, cementitious materials, and plastic - because these materials are better performing than the others-and their mechanical properties are tested the most. In the same way, if the focus is on rendering mortars, lighter materials are preferred, higher water to binder ratios are used, and thermal-hygrometric propertiesalong with capillary water adsorption-are investigated. In the current review, the records which were classified as rendering mortars were sourced from recycled plastic in seven counts out of eleven, sometimes mixed with other aggregates, mainly mineral. Lightweight mortars, in particular, were packaged with expanded and extruded polystyrene (EPS and XPS), expanded vermiculite, rubber powder, expanded perlite, polyester (PE), and plastic from cables. Finally, the only record which was suitable for thermal purposes contained wood shavings and sawdust, and it was characterized through thermal conductivity, resistance to vapor permeability, water capillary adsorption, dry bulk density, flexural and compressive strength, and drying shrinkage.

Because RA are generally lighter than NA—due to their higher porosity-they could be more appropriate for rendering mortars than for masonry ones, especially because the water adsorption of RA is much higher than that of NA [29], which can affect mechanical and durability properties of the conglomerates.

\subsection{Future Research Framework and Conclusions}

The methodology presented in this review can be applied to refined search strings in order to add details and to narrow the search field down to the RA categories which proved to be less analysed. Moreover, the collected data about RA can be further processed with the extraction of the information about the physical properties of the RA themselves, i.e., density, porosity, water adsorption and grain size distribution. These properties depend on the materials and the source of the RA and affect the properties of the conglomerates in which the RA is used. The overlapping of this new information and the old about the tested properties may be functional to distinguish the categories of RA which are 
more appropriate for rendering mortars, or for the applications where a lighter product is required, e.g., lightweight floor screeds. In this way, the RA potentiality would be further exploited and-because lower mechanical performances would be required-binders with less impact than cement could be used.

As regards the circular economy issues, greater efforts are required to develop the use of RA from industrial waste, in particular from building material factories. In fact, the possibility of using by-products as secondary raw materials to produce new building materials can lead to benefits for several stakeholders: economic and environmental benefits for the factories themselves, and social and environmental benefits for the civil community. This perspective can fit more properly to manufacturers who produce both bricks and pre-mixes, because they can reduce the waste production from the former and the natural resource consumption from the latter [30]. Nevertheless, this review found no products available on the market among the mixes collected; hence, some hypotheses about the obstacles to the development of commercial RA mortars can be formulated. In fact, despite the fact that the aforementioned results suggested that the RA can substitute the NA both in masonry and rendering mortars, few economic analyses have been found regarding the viability of these sustainable solutions. Some authors hypothesized that the barriers to the RAs' systematic use mainly derive from the variability of their source and characteristics, the lack of knowledge about their properties, and the absence of connections between academic and industrial issues [2]. Hence, one answer could be found in the designers' lack of confidence in building products which contain secondary raw materials, and their relative reliability. Because no economic demand is required, no economic supply is given.

In conclusion, the authors of the present study suggest further analyses regarding RA from building material factories and their suitability in mortars for lightweight applications, with specific focus on the economic feasibility of the process; for this purpose, the research group is currently working on an experimental campaign of the characterization of mortars packaged with waste from aerated autoclaved concrete production. Concerning the question about the lack of confidence in RA, a survey could be conducted involving the main stakeholders of the building process-designers, end customers, construction companies, and producers - in order to investigate, by a questionnaire, their opinions, confidence, and diffidence about waste reuse in building products. The results could then be used both by researchers and public officials to improve the awareness about the sustainable culture of recycling in order to give new birth to waste.

Author Contributions: Conceptualization, F.V. and M.N.; methodology and data curation, F.V.; writing—original draft preparation, F.V.; writing—review and editing, F.V. and M.N.; supervision, M.N. All authors have read and agreed to the published version of the manuscript.

Funding: This research received no external funding.

Institutional Review Board Statement: Not applicable.

Informed Consent Statement: Not applicable.

Conflicts of Interest: The authors declare no conflict of interest. 


\section{Appendix A}
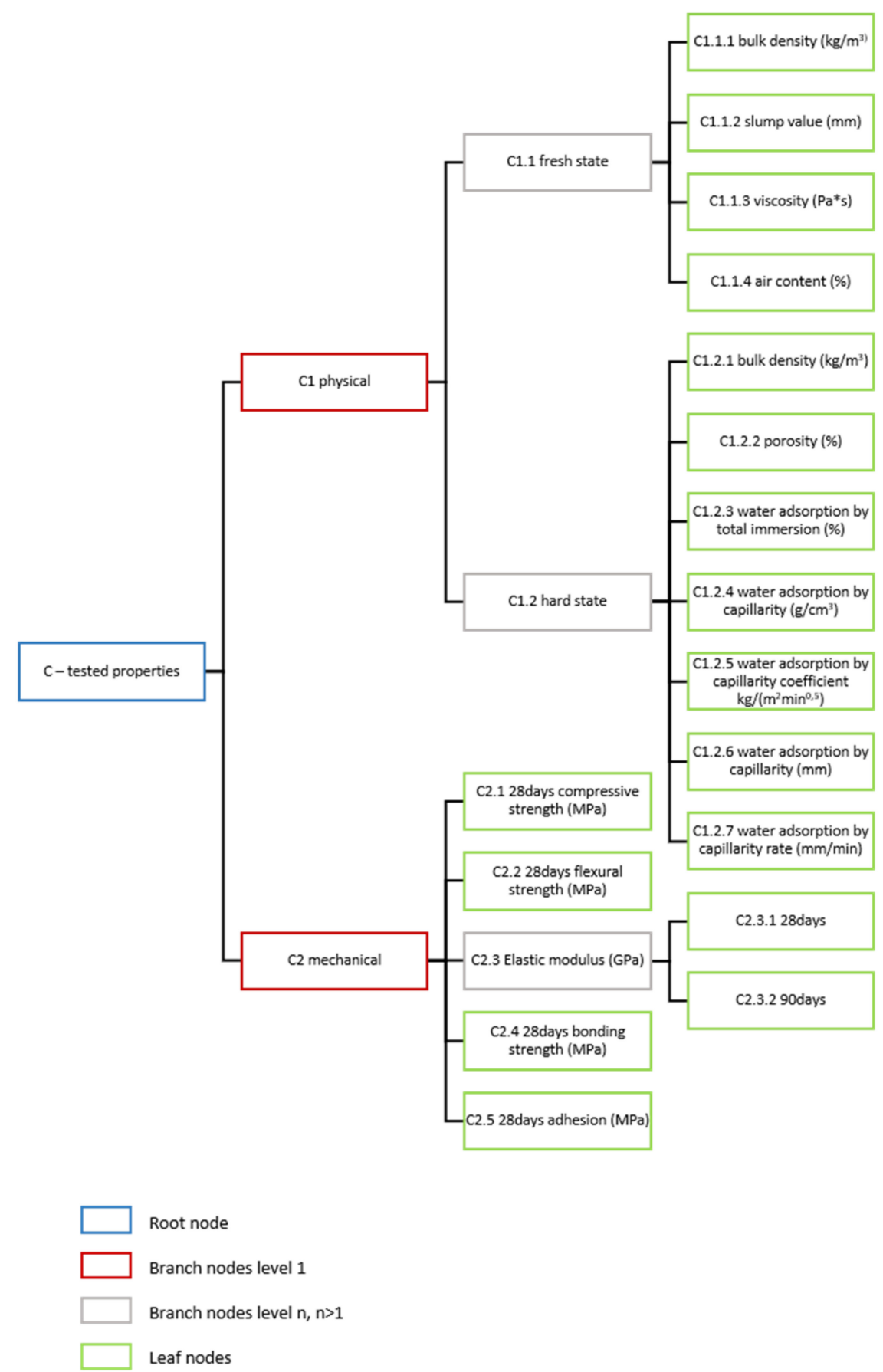

Figure A1. C-variable classification, first part. Two branch nodes out of six- $\mathrm{C} 1$ and $\mathrm{C} 2-$ are shown. 


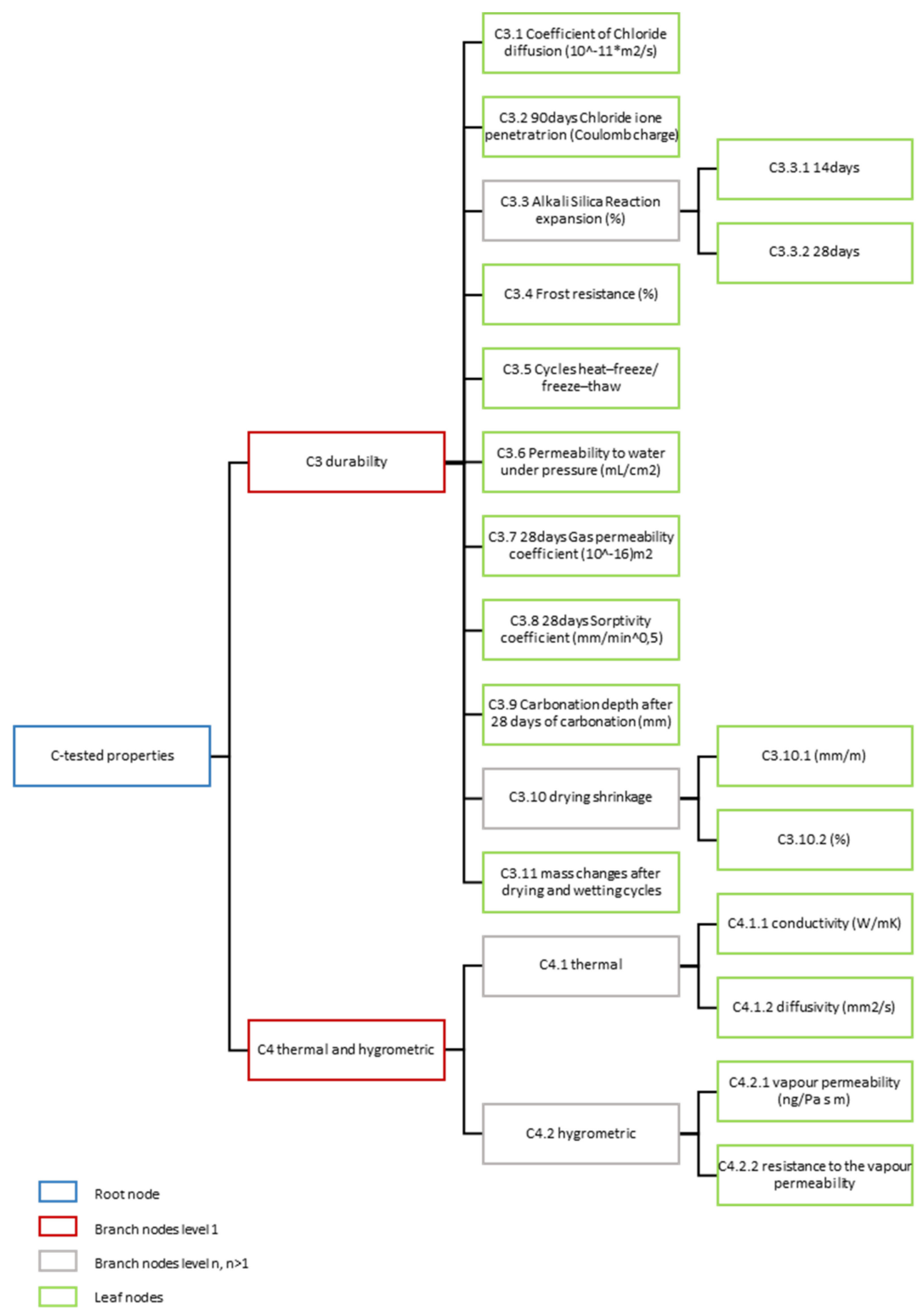

Figure A2. C-variable classification, second part. Two branch nodes out of six-C3 and C4-are shown. 


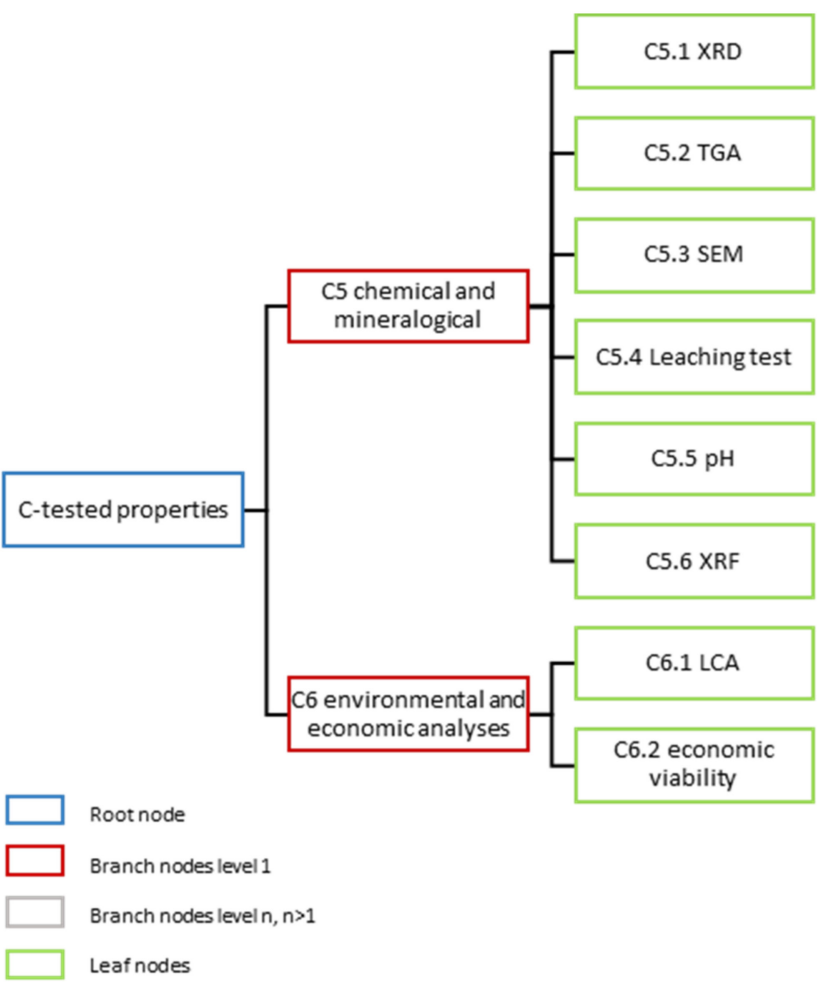

Figure A3. C-variable classification, third part. Two branch nodes out of six-C5 and C6-are shown.

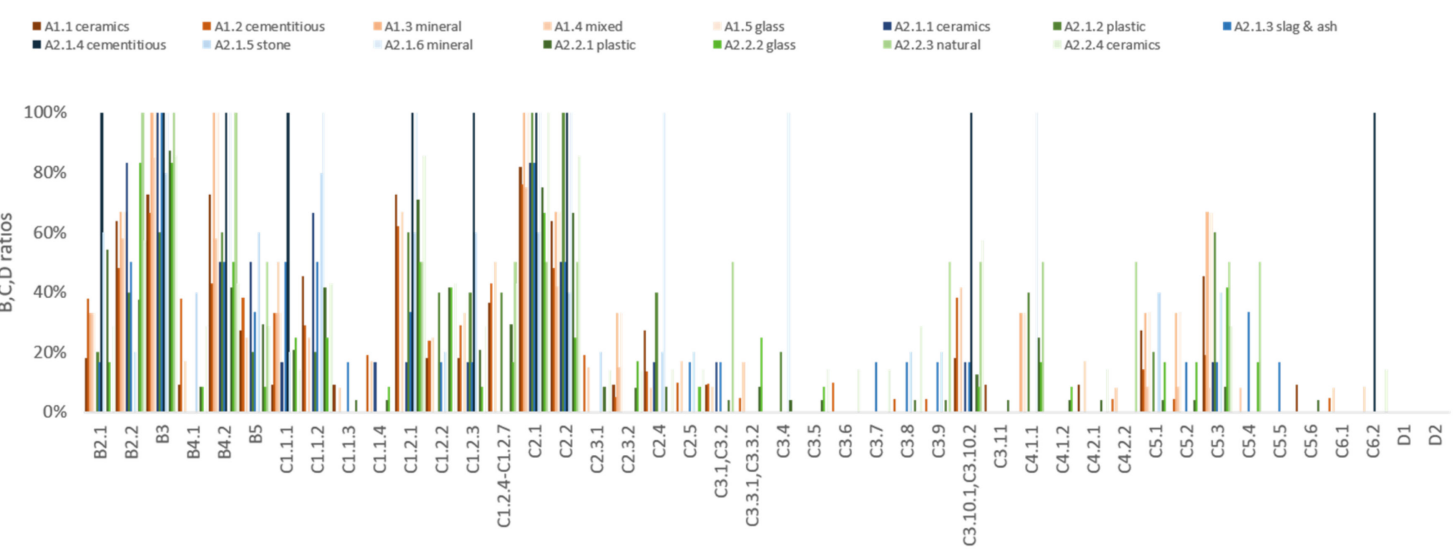

B,C,D leaf nodes

Figure A4. B, C, and D leaf nodes. The clustered bar chart plots the values of the B, C, and D ratios of the corresponding B, $\mathrm{C}$, and D leaf nodes.

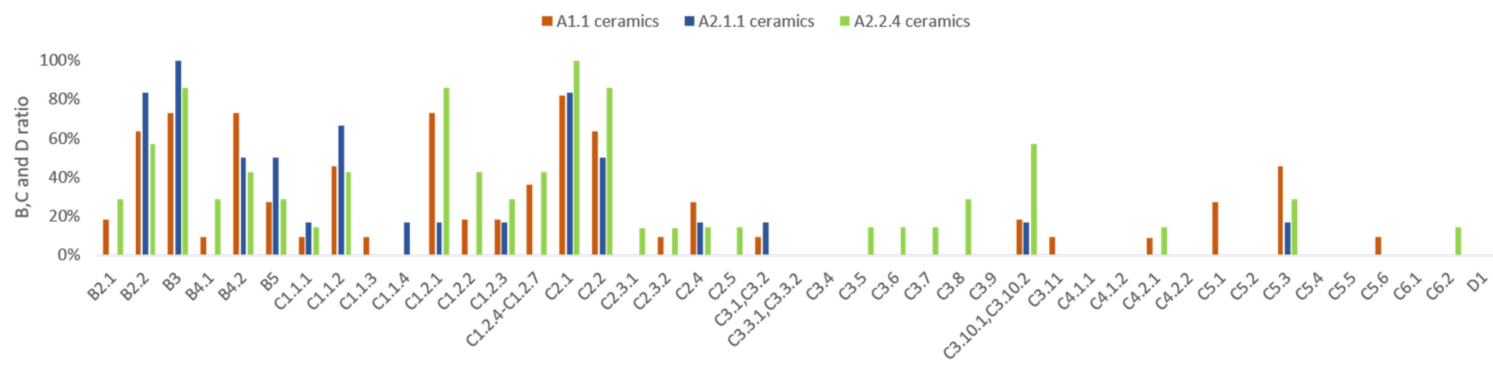

B,C,D leaf nodes

Figure A5. B, C, and D ratios of ceramic RA. The clustered bar chart plots the values of the B, C, and D ratios of the corresponding B, C, and D leaf nodes for ceramic RA. 


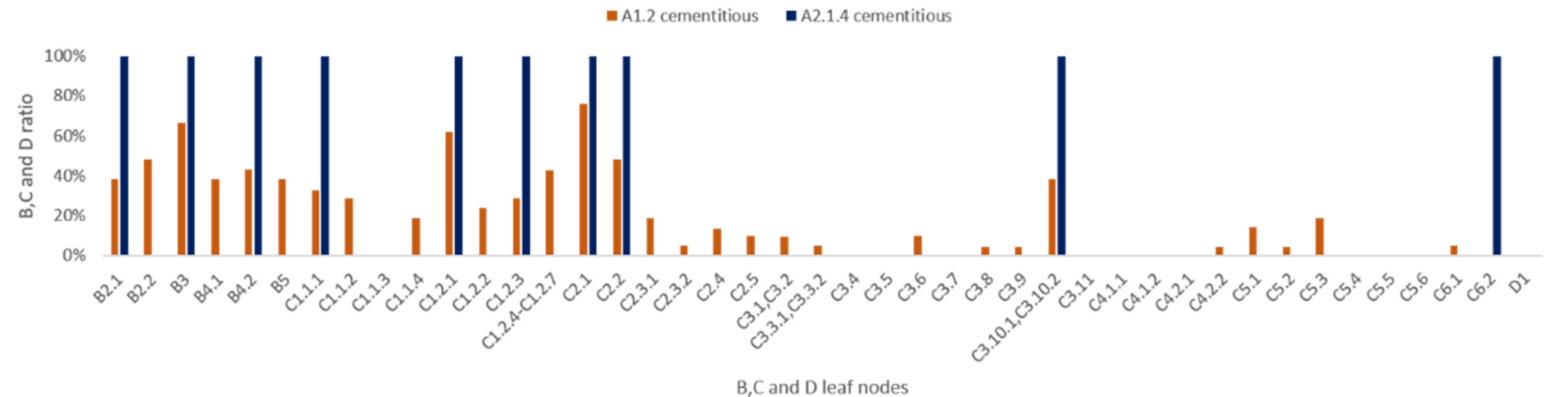

Figure A6. B, C, and D ratios of cementitious RA. The clustered bar chart plots the values of the B, C, and D ratios of the corresponding B, C, and D leaf nodes for cementitious RA.

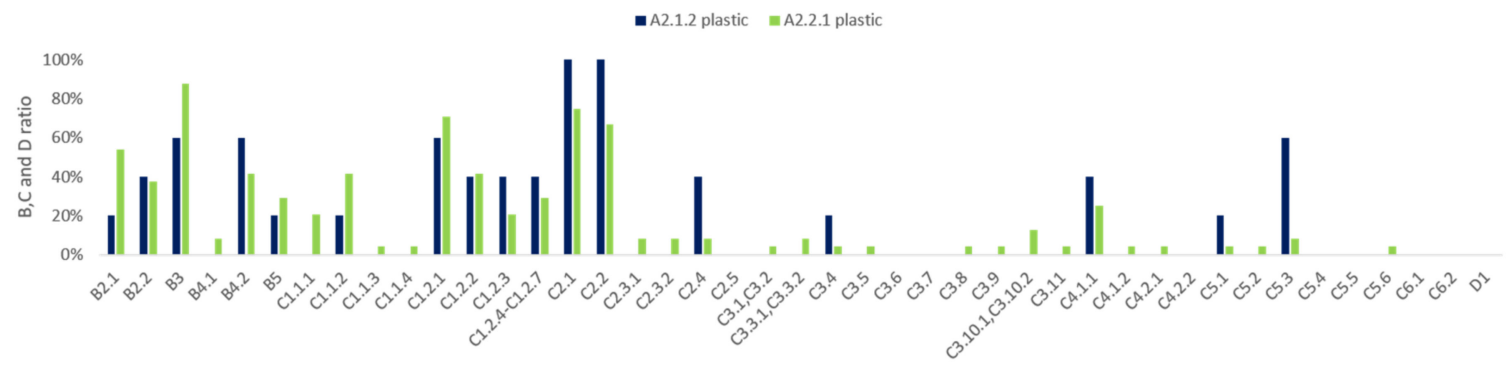

Figure A7. B, C, and D ratios of plastic RA. The clustered bar chart plots the values of the B, C and D ratios of the corresponding B, C, and D leaf nodes of plastic RA.

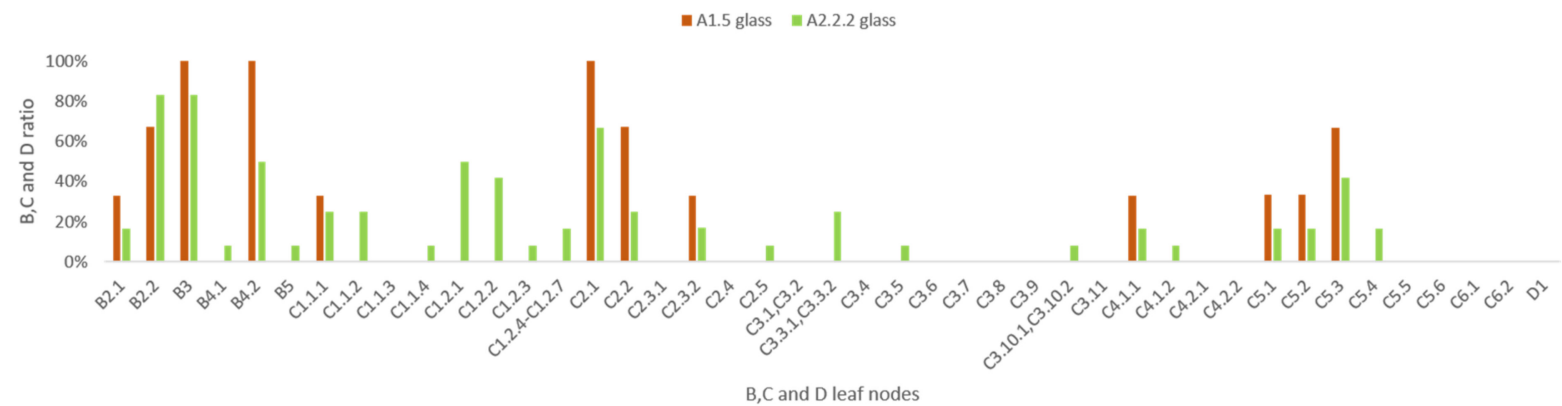

Figure A8. B, C, and D ratios of glass RA. The clustered bar chart plots the values of the B, C, and D ratios of the corresponding B, C, and D leaf nodes of glass RA. 


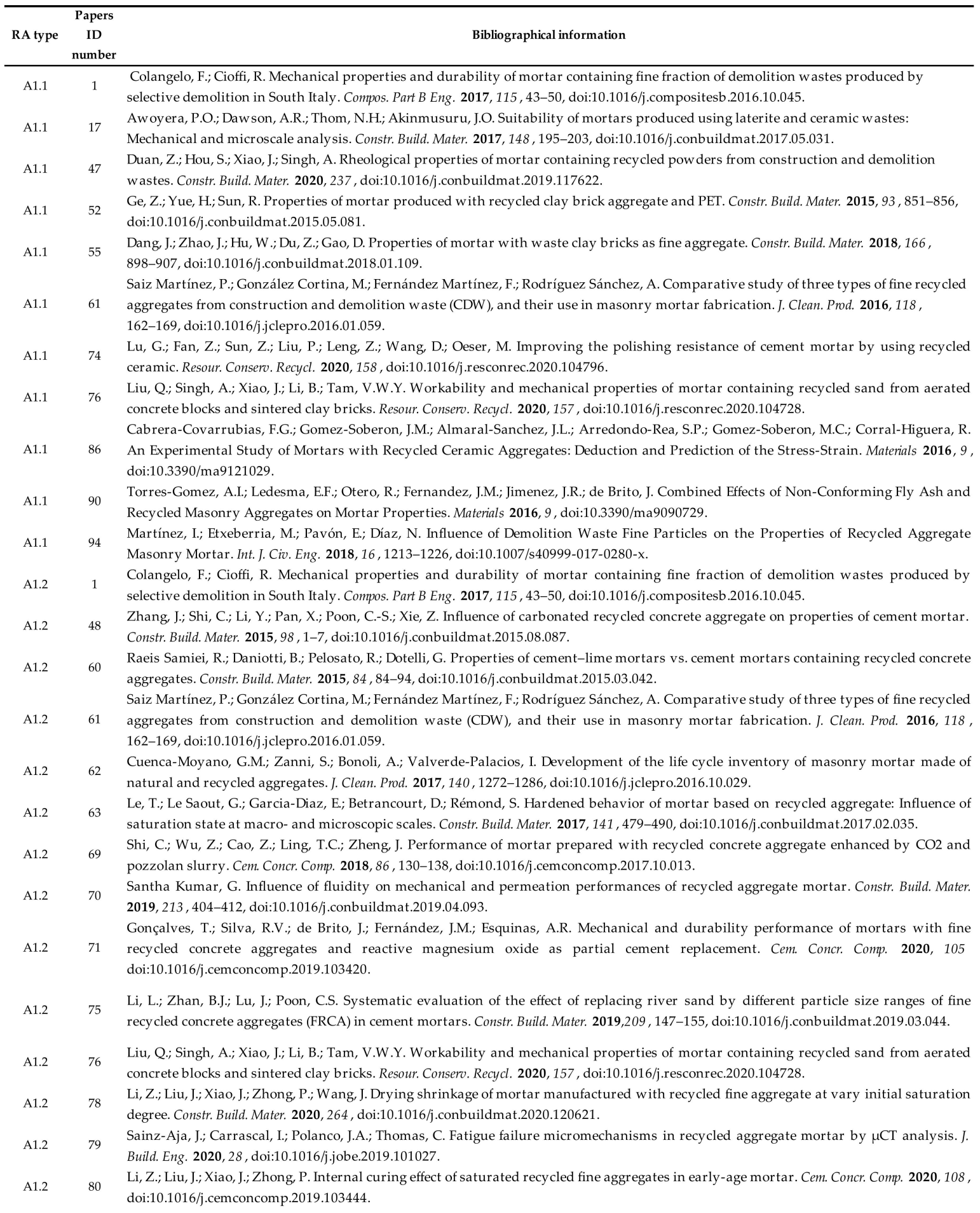

Figure A9. Cont. 
Cuenca-Moyano, G.M.; Martín-Pascual, J.; Martín-Morales, M.; Valverde-Palacios, I.; Zamorano, M. Effects of water to cement ratio,

recycled fine aggregate and air entraining/plasticizer admixture on masonry mortar properties. Constr. Build. Mater. 2020, 230. doi:10.1016/j.conbuildmat.2019.116929.

Ferreira, R.L.S.; Anjos, M.A.S.; Ledesma, E.F.; Pereira, J.E.S.; Nóbrega, A.K.C. Evaluation of the physical-mechanical properties of cementlime based masonry mortars produced with mixed recycled aggregates. Materiales de Construcción 2020, 70, doi:10.3989/mc.2020.02819.

Mora-Ortiz, R.S.; Munguia-Balvanera, E; Diaz, S.A.; Magana-Hernandez, F.; Del Angel-Meraz, E.; Bolaina-Juarez, A. Mechanical Behavior of Masonry Mortars Made with Recycled Mortar Aggregate. Materials 2020, 13, doi:10.3390/ma13102373.

94 Martínez, I.; Etxeberria, M.; Pavón, E; Díaz, N. Influence of Demolition Waste Fine Particles on the Properties of Recycled Aggregate Masonry Mortar. Int. J. Civ. Eng. 2018, 16, 1213-1226, doi:10.1007/s40999-017-0280-x.

100 Jiménez, J.R.; Fernández-Ledesma, E.; Ayuso, J.; Corinaldesi, V.; Iglesias-Godino, F.J. A proposal for the maximum use of recycled concrete sand in masonry mortar design. Materiales de Construcción 2016, 66, doi:10.3989/mc.2016.08414.

01 Fan, C.-C.; Huang, R.; Hwang, H.; Chao, S.-J. The Effects of Different Fine Recycled Concrete Aggregates on the Properties of Mortar. Materials 2015, 8, 2658-2672, doi:10.3390/ma8052658.

102 Roque, S.; Maia Pederneiras, C.; Brazao Farinha, C.; de Brito, J.; Veiga, R. Concrete-Based and Mixed Waste Aggregates in Rendering Mortars. Materials 2020, 13 , doi:10.3390/ma13081976.

Piña Ramírez, C.; del Río Merino, M.; Viñas Arrebola, C.; Vidales Barriguete, A.; Kosior-Kazberuk, M. Analysis of the mechanical

42 behaviour of the cement mortars with additives of mineral wool fibres from recycling of CDW. Constr. Build. Mater. 2019, 210, 56-62, doi:10.1016/j.conbuildmat.2019.03.062.

59 Piña Ramírez, C.; Vidales Barriguete, A.; Serrano Somolinos, R.; del Río Merino, M.; Atanes Sánchez, E. Analysis of fire resistance of cement mortars with mineral wool from recycling. Constr. Build. Mater. 2020, 265, doi:10.1016/j.conbuildmat.2020.120349.

Piña Ramírez, C.; Atanes Sánchez, E.; del Río Merino, M.; Viñas Arrebola, C.; Vidales Barriguete, A. Feasibility of the use of mineral wool

84 fibres recovered from CDW for the reinforcement of conglomerates by study of their porosity. Constr. Build. Mater. 2018, 191, 460-468, doi:10.1016/j.conbuildmat.2018.10.026

Colangelo, F.; Cioffi, R. Mechanical properties and durability of mortar containing fine fraction of demolition wastes produced by selective demolition in South Italy. Compos. Part B Eng. 2017, 115, 43-50, doi:10.1016/j.compositesb.2016.10.045.

7 Huang, L.; Yang, Z.; Li, Z.; Xu, Y.; Yu, L. Recycling of the end-of-life lightweight aggregate concrete (LWAC) with a novel approach. J. Clean. Prod. 2020, 275, doi:10.1016/j.jclepro.2020.123099.

31 Muñoz-Ruiperez, C.; Rodríguez, A.; Gutiérrez-González, S.; Calderón, V. Lightweight masonry mortars made with expanded clay and recycled aggregates. Constr. Build. Mater. 2016, 118, 139-145, doi:10.1016/j.conbuildmat.2016.05.065.

Lu, J.-X.; Shen, P.; Zheng, H.; Zhan, B.; Ali, H.A.; He, P.; Poon, C.S. Synergetic recycling of waste glass and recycled aggregates in cement mortars: Physical, durability and microstructure performance. Cem. Concr. Comp. 2020, 113, doi:10.1016/j.cemconcomp.2020.103632.

43 Yacoub, A.; Djerbi, A.; Fen-Chong, T. The effect of the drying temperature on water porosity and gas permeability of recycled sand mortar. Constr. Build. Mater. 2019, 214, 677-684, doi:10.1016/j.conbuildmat.2019.04.128.

Azevedo, A.R.G.; Cecchin, D.; Carmo, D.F.; Silva, F.C.; Campos, C.M.O.; Shtrucka, T.G.; Marvila, M.T.; Monteiro, S.N. Analysis of the 45 compactness and properties of the hardened state of mortars with recycling of construction and demolition waste (CDW). J. Mater. Res. Technol. 2020, 9, 5942-5952, doi:10.1016/j.jmrt.2020.03.122.

Le, M.T.; Tribout, C.; Escadeillas, G. Durability of mortars with leftover recycled sand. Constr. Build. Mater. 2019, 215, 391-400, doi:10.1016/j.conbuildmat.2019.04.179.

47 Duan, Z.; Hou, S.; Xiao, J.; Singh, A. Rheological properties of mortar containing recycled powders from construction and demolition wastes. Constr. Build. Mater. 2020, 237, doi:10.1016/j.conbuildmat.2019.117622.

50 Zhao, Z.; Remond, S.; Damidot, D.; Xu, W. Influence of fine recycled concrete aggregates on the properties of mortars. Constr. Build. Mater. 2015, 81, 179-186, doi:10.1016/j.conbuildmat.2015.02.037.

Saiz Martínez, P.; González Cortina, M.; Fernández Martínez, F.; Rodríguez Sánchez, A. Comparative study of three types of fine recycled 61 aggregates from construction and demolition waste (CDW), and their use in masonry mortar fabrication. J. Clean. Prod. 2016, 118, 162-169, doi:10.1016/j.jclepro.2016.01.059.

64 Jesus, S.; Maia, C.; Brazão Farinha, C.; de Brito, J.; Veiga, R. Rendering mortars with incorporation of very fine aggregates from construction and demolition waste. Constr. Build. Mater. 2019,229, doi:10.1016/j.conbuildmat.2019.116844.

72 Ferreira, R.L.S.; Anjos, M.A.S.; Nóbrega, A.K.C.; Pereira, J.E.S.; Ledesma, E.F. The role of pow der content of the recy cled aggregates of CDW in the behaviour of rendering mortars. Constr. Build. Mater. 2019, 208, 601-612, doi:10.1016/j.conbuildmat.2019.03.058.

79 Sainz-Aja, J.; Carrascal, I.; Polanco, J.A.; Thomas, C. Fatigue failure micromechanisms in recycled aggregate mortar by $\mu \mathrm{CT}$ analysis. J. Build. Eng. 2020, 28 , doi:10.1016/j.jobe.2019.101027.

Yedra Álvarez, E; Ferrández Vega, D.; Saiz Martínez, P.; Morón Fernández, C. Low cost system for measuring the evolution of mechanical properties in cement mortars as a function of mixing water. Constr. Build. Mater. 2020, 244, doi:10.1016/j.conbuildmat.2020.118127.

92 Cortina, M.G.; Martínez, P.S.; Martínez, F.F. Environmental Improvement in Use of Fine Fraction Recycled Aggregates as a Raw Material in Masonry Mortar Fabrication. Open Constr. Build. Technol. J. 2017, 11, 371-380, doi:10.2174/1874836801711010371.

95 Saiz-Martínez, P.; González-Cortina, M.; Fernández-Martínez, F. Characterization and influence of fine recycled aggregates on masonry mortars properties. Materiales de Construcción 2015, 65 , doi:10.3989/mc.2015.06014.

Figure A9. Cont. 
Martínez, I.; Etxeberria, M.; Pavón, E; Díaz, N. Analysis of the properties of masonry mortars made with recycled fine aggregates for use as a new building material in Cuba. Revista de la Construcción 2016, 15, 9-21, doi:10.4067/s0718-915x2016000100001.

98 Mobili, A.; Giosuè, C.; Corinaldesi, V.; Tittarelli, F. Bricks and Concrete Wastes as Coarse and Fine Aggregates in Sustainable Mortars. Adv. Mater. Sci. Eng. 2018, 2018, 1-11, doi:10.1155/2018/8676708.

99 Raini, I.; Jabrane, R.; Mesrar, L.; Akdim, M. Evaluation of mortar properties by combining concrete and brick wastes as fine aggregate. Case Stud. Constr. Mater. 2020, 13, doi:10.1016/j.cscm.2020.e00434.

102 Roque, S.; Maia Pederneiras, C.; Brazao Farinha, C.; de Brito, J.; Veiga, R. Concrete-Based and Mixed Waste Aggregates in Rendering Mortars. Materials 2020, 13, doi:10.3390/ma13081976.

Piña Ramírez, C.; del Río Merino, M.; Viñas Arrebola, C.; Vidales Barriguete, A.; Kosior-Kazberuk, M. Analysis of the mechanical

42 behaviour of the cement mortars with additives of mineral wool fibres from recycling of CDW. Constr. Build. Mater. 2019, 210, 56-62, doi:10.1016/j.conbuildmat.2019.03.062.

59 Piña Ramírez, C.; Vidales Barriguete, A.; Serrano Somolinos, R.; del Río Merino, M.; Atanes Sánchez, E. Analysis of fire resistance of cement mortars with mineral wool from recycling. Constr. Build. Mater. 2020, 265, doi:10.1016/j.conbuildmat.2020.120349.

Piña Ramírez, C.; Atanes Sánchez, E; del Río Merino, M.; Viñas Arrebola, C.; Vidales Barriguete, A. Feasibility of the use of mineral wool

84 fibres recovered from CDW for the reinforcement of conglomerates by study of their porosity. Constr. Build. Mater. 2018, 191, 460-468, doi:10.1016/j.conbuildmat.2018.10.026.

15 Li, L.G.; Zhuo, Z.Y.; Kwan, A.K.H.; Zhang, T.S.; Lu, D.G. Cementing efficiency factors of ceramic polishing residue in compressive strength and chloride resistance of mortar. Powder Technol. 2020,367, 163-171, doi:10.1016/j.powtec.2020.03.050.

24 Li, L.G.; Zhuo, Z.Y.; Zhu, J.; Kwan, A.K.H. Adding ceramic polishing waste as paste substitute to improve sulphate and shrinkage resistances of mortar. Powder Technol. 2020,362,149-156, doi:10.1016/j.pow tec.2019.11.117.

37 Ge, Z.; Feng, Y.; Zhang, H.; Xiao, J.; Sun, R.; Liu, X. Use of recycled fine clay brick aggregate as internal curing agent for low water to cement ratio mortar. Constr. Build. Mater. 2020, 264 doi:10.1016/j.conbuildmat.2020.120280A.

77 Nasr, M.S.; Shubbar, A.A.; Abed, Z.A.-A.R.; Ibrahim, M.S. Properties of eco-friendly cement mortar contained recycled materials from different sources. J. Build. Eng. 2020, 31, doi:10.1016/j.jobe.2020.101444.

88 Gómez-Soberón, M.C.; Corral-Higuera, R.; Almaral-Sánchez, J.L.; Gómez-Soberón, J.M.; Cabrera-Covarrubias, F.G. Implementation of Interaction Diagram of the Properties in Fresh for Mortars with Ceramic Aggregates. Period. Polytech. Civ. 2016, 61, doi:10.3311/PPci.9651.

97 Ulewicz, M.; Halbiniak, J. Application of waste from utilitarian ceramics for production of cement mortar and concrete. Physicochem. Prob. Miner. Proces. 2016, 52, 1002-1010, doi:10.5277/ppmp160237.

4 Lanzón, M.; Cnudde, V.; De Kock, T.; Dewanckele, J. Microstructural examination and potential application of rendering mortars made of tire rubber and expanded polystyrene wastes. Constr. Build. Mater. 2015, 94, 817-825, doi:10.1016/j.conbuildmat.2015.07.086.

$5 \quad$ Xu, F.; Peng, C.; Zhu, J.; Chen, J. Design and evaluation of polyester fiber and SBR latex compound-modified perlite mortar with rubber pow der. Constr. Build. Mater. 2016, 127, 751-761, doi:10.1016/j.conbuildmat.2016.10.060.

22 Del Río Merino, M.; Santa Cruz Astorqui, J.; Villoria Sáez, P.; Santos Jiménez, R.; González Cortina, M. Eco plaster mortars with addition of waste for high hardness coatings. Constr. Build. Mater. 2018, 158, 649-656, doi:10.1016/j.conbuildmat.2017.10.037.

28 Berkak, H.; Bederina, M.; Makhloufi, Z. Physico-mechanical and microstructural properties of an eco-friendly limestone mortar modified with styrene-polyacrylic latex. J. Build. Eng. 2020, 32 , doi:10.1016/j.jobe.2020.101463.

29 Koksal, F.; Mutluay, E.; Gencel, O. Characteristics of isolation mortars produced with expanded vermiculite and waste expanded polystyrene. Constr. Build. Mater. 2020, 236, doi:10.1016/j.conbuildmat.2019.117789.

9 Santamaría-Vicario, I.; Rodríguez, A.; Gutiérrez-González, S.; Calderón, V. Design of masonry mortars fabricated concurrently with different steel slag aggregates. Constr. Build. Mater. 2015, 95 , 197-206, doi:10.1016/j.conbuildmat.2015.07.164.

16 Güneyisi, E.; Gesoğlu, M.; Altan, İ.; Öz, H.Ö. Utilization of cold bonded fly ash lightweight fine aggregates as a partial substitution of natural fine aggregate in self-compacting mortars. Constr. Build. Mater. 2015, 74, 9-16, doi:10.1016/j.conbuildmat.2014.10.021.

Bodor, M.; Santos, R.M.; Cristea, G.; Salman, M.; Cizer, Ö.; Iacobescu, R.I.; Chiang, Y.W.; van Balen, K.; Vlad, M.; van Gerven, T. Laboratory 20 investigation of carbonated BOF slag used as partial replacement of natural aggregate in cement mortars. Cem. Concr. Comp. 2016, 65 , 55-66, doi:10.1016/j.cemconcomp.2015.10.002.

25 Baeza, F.J.; Galao, O.; Vegas, I.J.; Cano, M.; Garcés, P. Influence of recycled slag aggregates on the conductivity and strain sensing capacity of carbon fiber reinforced cement mortars. Constr. Build. Mater. 2018, 184,311-319, doi:10.1016/j.conbuildmat.2018.06.218.

41 Santamaría, A.; González, J.J.; Losáñez, M.M.; Skaf, M.; Ortega-López, V. The design of self-compacting structural mortar containing steelmaking slags as aggregate. Cem. Concr. Comp. 2020, 111, doi:10.1016/j.cemconcomp.2020.103627.

68 Yang, T.; Zhang, Z.; Wang, Q.; Wu, Q. ASR potential of nickel slag fine aggregate in blast furnace slag-fly ash geopolymer and Portland cement mortars. Constr. Build. Mater. 2020,262, doi:10.1016/j.conbuildmat.2020.119990.

31 Muñoz-Ruiperez, C.; Rodríguez, A.; Gutiérrez-González, S.; Calderón, V. Lightweight masonry mortars made with expanded clay and recycled aggregates. Constr. Build. Mater. 2016, 118, 139-145, doi:10.1016/j.conbuildmat.2016.05.065.

23 Li, L.G.; Huang, Z.H.; Tan, Y.P.; Kwan, A.K.H.; Liu, F. Use of marble dust as paste replacement for recycling waste and improving durability and dimensional stability of mortar. Constr. Build. Mater. 2018, 166 , 423-432, doi:10.1016/j.conbuildmat.2018.01.154.

Figure A9. Cont. 
A2.1.5 33 Chouhan, H.S.; Kalla, P.; Nagar, R.; Gautam, P.K. Gainful utilization of dimensional limestone waste as fine aggregate in cement mortar

A2.1.5 35 Nascimento, A.S.; dos Santos, C.P.; de Melo, F.M.C.; Oliveira, V.G.A.; Betânio Oliveira, R.M.P.; Macedo, Z.S.; de Oliveira, H.A. Production of plaster mortar with incorporation of granite cutting wastes. J. Clean. Prod. 2020, 265, doi:10.1016/j.jclepro.2020.121808.

A2.1.5 44 Li, L.G.; Huang, Z.H.; Tan, Y.P.; Kwan, A.K.H.; Chen, H.Y. Recycling of marble dust as paste replacement for improving strength, 44 microstructure and eco-friendliness of mortar. J. Clean. Prod. 2019, 210, 55-65, doi:10.1016/j.jclepro.2018.10.332.

A2.1.5 77 Nasr, M.S.; Shubbar, A.A.; Abed, Z.A.-A.R.; Ibrahim, M.S. Properties of eco-friendly cement mortar contained recycled materials from different sources. J. Build. Eng. 2020, 31, doi:10.1016/j.jobe.2020.101444.

A2.1.6 $5 \quad$ Xu, F.; Peng, C.; Zhu, J.; Chen, J. Design and evaluation of polyester fiber and SBR latex compound-modified perlite mortar with rubber pow der. Constr. Build. Mater. 2016, 127, 751-761, doi:10.1016/j.conbuildmat.2016.10.060.

A2.2.1 2 Si, R.; Guo, S.; Dai, Q. Durability performance of rubberized mortar and concrete with NaOH-Solution treated rubber particles. Constr. Build. Mater. 2017, 153, 496-505, doi:10.1016/j.conbuildmat.2017.07.085.

A2.2.1 4 Lanzón, M.; Cnudde, V.; De Kock, T.; Dew anckele, J. Microstructural examination and potential application of rendering mortars made of tire rubber and expanded polystyrene wastes. Constr. Build. Mater. 2015, 94, 817-825, doi:10.1016/j.conbuildmat.2015.07.086.

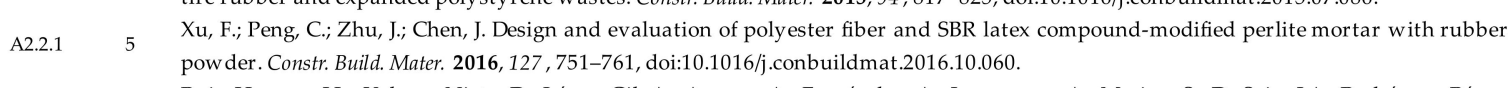

Ruiz-Herrero, J.L.; Velasco Nieto, D.; López-Gil, A.; Arranz, A.; Fernández, A.; Lorenzana, A.; Merino, S.; De Saja, J.A.; Rodríguez-Pérez,

A2.2.1 6 M.Á. Mechanical and thermal performance of concrete and mortar cellular materials containing plastic waste. Constr. Build. Mater. 2016, 104, 298-310, doi:10.1016/j.conbuildmat.2015.12.005.

Angelin, A.F.; Lintz, R.C.C.; Gachet-Barbosa, L.A.; Osório, W.R. The effects of porosity on mechanical behavior and water absorption of an A2.2.1 10 environmentally friendly cement mortar with recycled rubber. Constr. Build. Mater. 2017, 151, 534-545, doi:10.1016/j.conbuildmat.2017.06.061.

A2.2.1 11 Al-Tulaian, B.S.; Al-Shannag, M.J.; Al-Hozaimy, A.R. Recycled plastic waste fibers for reinforcing Portland cement mortar. Constr. Build. Mater. 2016, 127, 102-110, doi:10.1016/j.conbuildmat.2016.09.131.

A2.2.1

13 Coppola, B.; Courard, L.; Michel, F.; Incarnato, L.; Di Maio, L. Investigation on the use of foamed plastic waste as natural aggregates replacement in lightweight mortar. Compos. Part B Eng. 2016, 99, 75-83, doi:10.1016/j.compositesb.2016.05.058.

A2.2.1

Boukour, S.; Benmalek, M.L. Performance evaluation of a resinous cement mortar modified with crushed clay brick and tire rubber aggregate. Constr. Build. Mater. 2016, 120,473-481, doi:10.1016/j.conbuildmat.2016.05.119.

ang, S.; Ukrainczyk, N.; Koenders, E.A.B. Thermal conductivity of crumb-rubber-modified mortar using an inverse meso-scale heat conduction model. Constr. Build. Mater. 2019, 212, 522-530, doi:10.1016/j.conbuildmat.2019.04.011.

A2.2.1 21 Fantilli, A.P.; Chiaia, B. Mechanical performances of mortar prisms and concrete slabs incorporating rubber aggregates. Mech. Res. Commun. 2018, 92 , 118-123, doi:10.1016/j.mechrescom.2018.08.013.

A2.2.1 26 Farinha, C.B.; de Brito, J.; Veiga, R. Assessment of glass fibre reinforced polymer waste reuse as filler in mortars. J. Clean. Prod. 2019, 210 1579-1594, doi:10.1016/j.jclepro.2018.11.080.

Badache, A.; Benosman, A.S.; Senhadji, Y.; Mouli, M. Thermo-physical and mechanical characteristics of sand-based lightweight

A2.2.1 27 composite mortars with recycled high-density polyethylene (HDPE). Constr. Build. Mater. 2018, 163, 40-52, doi:10.1016/j.conbuildmat.2017.12.069.

A2.2.1 $30 \quad$ Gheni, A.A.; Alghazali, H.H.; ElGawady, M.A.; Myers, J.J.; Feys, D. Durability properties of cleaner cement mortar with by-products of tire recycling. J. Clean. Prod. 2019, 213,1135-1146, doi:10.1016/j.jclepro.2018.12.260.

Spósito, F.A.; Higuti, R.T.; Tashima, M.M.; Akasaki, J.L.; Melges, J.L.P.; Assunção, C.C.; Bortoletto, M.; Silva, R.G.; Fioriti, C.F. Incorporation of PET wastes in rendering mortars based on Portland cement/hydrated lime. J. Build. Eng. 2020, 32, doi:10.1016/j.jobe.2020.101506.

Hita, P.R.-d.; Pérez-Gálvez, F.; Morales-Conde, M.J.; Pedreño-Rojas, M.A. Reuse of plastic waste of mixed polypropylene as aggregate in 39 mortars for the manufacture of pieces for restoring jack arch floors with timber beams. J. Clean. Prod. 2018, 198, 1515-1525, doi:10.1016/j.jclepro.2018.07.065.

A2.2.1

49 Kaur, G.; Pavia, S. Physical properties and microstructure of plastic aggregate mortars made with acrylonitrile-butadiene-styrene (ABS), polycarbonate (PC), polyoxymethylene (POM) and ABS/PC blend waste. J. Build. Eng. 2020, 31, doi:10.1016/j.jobe.2020.101341. Ge, Z.; Yue, H.; Sun, R. Properties of mortar produced with recycled clay brick aggregate and PET. Constr. Build. Mater. 2015, 93, 851-856, doi:10.1016/j.conbuildmat.2015.05.081.

Rodin, H.; Nassiri, S.; Englund, K.; Fakron, O.; Li, H. Recycled glass fiber reinforced polymer composites incorporated in mortar for improved mechanical performance. Constr. Build. Mater. 2018, 187, 738-751, doi:10.1016/j.conbuildmat.2018.07.169. doi:10.1016/j.conbuildmat.2018.11.070.

Shi, X.; Brescia-Norambuena, L.; Tavares, C.; Grasley, Z. Semicircular bending fracture test to evaluate fracture properties and ductility of cement mortar reinforced by scrap tire recycled steel fiber. Eng. Fract. Mech. 2020, 236, doi:10.1016/j.engfracmech.2020.107228.

Di Mundo, R.; Seara-Paz, S.; González-Fonteboa, B.; Notarnicola, M. Masonry and render mortars with tyre rubber as aggregate: Fresh state rheology and hardened state performances. Constr. Build. Mater. 2020, 245 , doi:10.1016/j.conbuildmat.2020.118359.

Figure A9. Cont. 


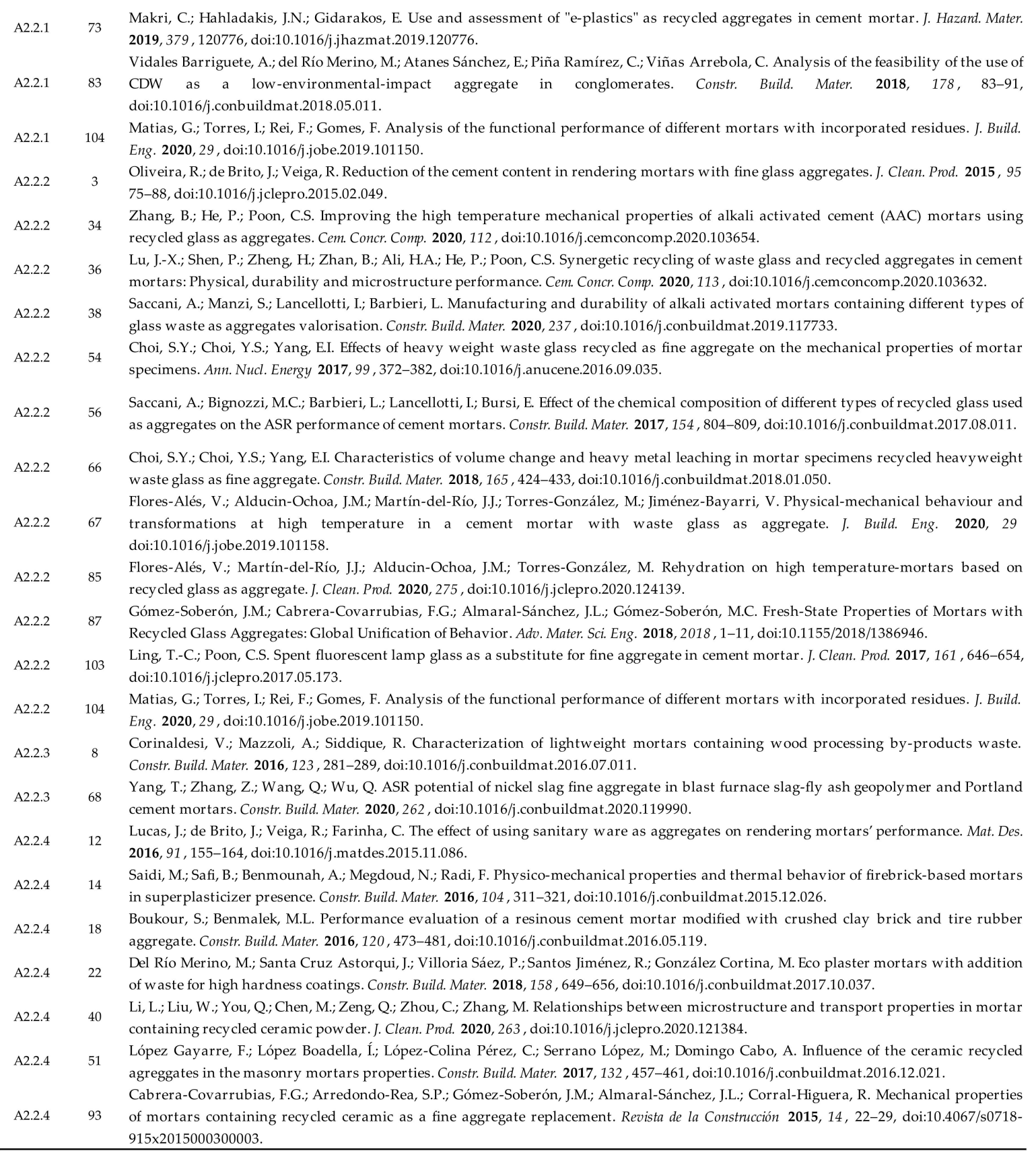

Figure A9. Set of collected papers. The A-leaf nodes, ID numbers and bibliographical information are reported. Papers were sorted by their A-leaf nodes.

\section{References}

1. Silva, R.V.; de Brito, J.; Dhir, R.K. Performance of cementitious renderings and masonry mortars containing recycled aggregates from construction and demolition wastes. Constr. Build. Mater. 2016, 105, 400-415. [CrossRef]

2. Chen, W.; Jin, R.; Xu, Y.; Wanatowski, D.; Li, B.; Yan, L.; Pan, Z.; Yang, Y. Adopting recycled aggregates as sustainable construction materials: A review of the scientific literature. Constr. Build. Mater. 2019, 218, 483-496. [CrossRef]

3. Meek, A.H.; Elchalakani, M.; Beckett, C.T.S.; Grant, T. Alternative stabilized rammed earth materials incorporating recycled waste and industrial by-products: Life cycle assessment. Constr. Build. Mater. 2021, 267. [CrossRef]

4. Nicolella, M.; Scognamillo, C.; Vitale, F. Valutazione comparativa delle prestazioni meccaniche di malte confezionate con inerti da riciclo. In New Horizons for Sustainable Architecture, 1st ed.; Cascone, S.M., Margani, G., Sapienza, V., Eds.; Edicom Edizioni: Gorizia, Italy, 2020; pp. 742-756.

5. Srivastava, A.; Singh, S.K. Utilization of alternative sand for preparation of sustainable mortar: A review. J. Clean. Prod. 2020, 253. [CrossRef] 
6. Gálvez-Martos, J.L.; Styles, D.; Schoenberger, H.; Zeschmar-Lahl, B. Construction and demolition waste best management practice in Europe. Resour. Conserv. Recycl. 2018, 136, 166-178. [CrossRef]

7. López Ruiz, L.A.; Roca Ramón, X.; Gassó Domingo, S. The circular economy in the construction and demolition waste sector-A review and an integrative model approach. J. Clean. Prod. 2020, 248, 119238. [CrossRef]

8. Almeshal, I.; Tayeh, B.A.; Alyousef, R.; Alabduljabbar, H.; Mustafa Mohamed, A.; Alaskar, A. Use of recycled plastic as fine aggregate in cementitious composites: A review. Constr. Build. Mater. 2020, 253. [CrossRef]

9. Silva, R.V.; de Brito, J.; Dhir, R.K. Use of recycled aggregates arising from construction and demolition waste in new construction applications. J. Clean. Prod. 2019, 236. [CrossRef]

10. Bai, G.; Zhu, C.; Liu, C.; Liu, B. An evaluation of the recycled aggregate characteristics and the recycled aggregate concrete mechanical properties. Constr. Build. Mater. 2020, 240. [CrossRef]

11. Dong, Q.; Wang, G.; Chen, X.; Tan, J.; Gu, X. Recycling of steel slag aggregate in Portland cement concrete: An overview. J. Clean. Prod. 2021, 282. [CrossRef]

12. Silva, R.V.; de Brito, J.; Dhir, R.K. Availability and processing of recycled aggregates within the construction and demolition supply chain: A review. J. Clean. Prod. 2017, 143, 598-614. [CrossRef]

13. Faraj, R.H.; Hama Ali, H.F.; Sherwani, A.F.H.; Hassan, B.R.; Karim, H. Use of recycled plastic in self-compacting concrete: A comprehensive review on fresh and mechanical properties. J. Build. Eng. 2020, 30. [CrossRef]

14. Li, X.; Ling, T.-C.; Hung Mo, K. Functions and impacts of plastic/rubber wastes as eco-friendly aggregate in concrete. A review. Constr. Build. Mater. 2020, 240. [CrossRef]

15. Gayarre, F.L.; González, J.S.; Pérez, C.L.C.; Serrano López, M.A.; Ros, P.S.; Martínez-Barrera, G. Shrinkage and creep in structural concrete with recycled brick aggregates. Constr. Build. Mater. 2019, 228. [CrossRef]

16. Le, H.B.; Bui, Q.B. Recycled aggregate concretes. A state-of-the-art from the microstructure to the structural performance. Constr Build. Mater. 2020, 257. [CrossRef]

17. Xuan, D.X.; Schlangen, E.; Molenaar, A.A.A.; Houben, L.J.M. Influence of quality and variation of recycled masonry aggregates on failure behavior of cement treated demolition waste. Constr. Build. Mater. 2014, 71, 521-527. [CrossRef]

18. Debbarma, S.; Ransinchung, G.D.; Singh, S.; Sahdeo, S.K. Utilization of industrial and agricultural wastes for productions of sustainable roller compacted concrete pavement mixes containing reclaimed asphalt pavement aggregates. Resour. Conserv. Recycl. 2020, 152. [CrossRef]

19. Harrison, E.; Berenjian, A.; Seifan, M. Recycling of waste glass as aggregate in cement-based materials. Environ. Sci. Ecotechnol. 2020, 4. [CrossRef]

20. Moher, D.; Liberati, A.; Tetzlaff, J.; Altman, D.G. Preferred reporting items for systematic reviews and meta-analyses: The PRISMA statement. BMJ 2009, 7716, 332-336.

21. Jiménez, J.R.; Ayuso, J.; López, M.; Fernández, J.M.; de Brito, J. Use of fine recycled aggregates from ceramic waste in masonry mortar manufacturing. Constr. Build. Mater. 2013, 40, 679-690. [CrossRef]

22. Afroughsabet, V.; Biolzi, L.; Ozbakkaloglu, T. Influence of double hooked-end steel fibers and slag on mechanical and durability properties of high performance recycled aggregate concrete. Compos. Struct. 2017, 181, 273-284. [CrossRef]

23. Chakradhara Rao, M. Properties of recycled aggregate and recycled aggregate concrete: Effect of parent concrete. Asian J. Civ. Eng. 2018, 19, 103-110. [CrossRef]

24. Kou, S.C.; Poon, C.S. Effect of the quality of parent concrete on the properties of high performance recycled aggregate concrete. Constr. Build. Mater. 2015, 77, 501-508. [CrossRef]

25. Haach, V.G.; Vasconcelos, G.; Lourenço, P.B. Influence of aggregates grading and water/cement ratio in workability and hardened properties of mortars. Constr. Build. Mater. 2011, 25, 2980-2987. [CrossRef]

26. Beltrán, M.G.; Agrela, F.; Barbudo, A.; Ayuso, J.; Ramírez, A. Mechanical and durability properties of concretes manufactured with biomass bottom ash and recycled coarse aggregates. Constr. Build. Mater. 2014, 72, 231-238. [CrossRef]

27. Thomas, C.; Setién, J.; Polanco, J.A.; Alaejos, P.; Sánchez de Juan, M. Durability of recycled aggregate concrete. Constr. Build. Mater. 2013, 40, 1054-1065. [CrossRef]

28. Olorunsogo, F.T.; Padayachee, N. Performance of recycled aggregate concrete monitored by durability indexes. Cem. Concr. Res. 2002, 32, 179-185. [CrossRef]

29. McNeil, K.; Kang, T.H.K. Recycled Concrete Aggregates: A Review. Int. J. Concr. Struct. Mater. 2013, 7, 61-69. [CrossRef]

30. Nicolella, M.; Pino, A.; Scognamillo, C.; Vitale, F. Feasibility Study on the Production of Sustainable Mortars Packaged with Recycled AAC Aggregates. In IOP Conference Series: Materials Science and Engineering; IOP Publishing: Bristol, UK, 2020; Volume 960. 